\title{
Enhanced SARS-CoV-2 Neutralization by Secretory IgA in vitro
}

${ }^{1}$ Laboratory of Molecular Immunology, The Rockefeller University, New York, NY, USA.

${ }^{2}$ Laboratory of Retrovirology, The Rockefeller University, New York, NY, USA.

${ }^{3}$ Laboratory of Virology and Infectious Disease, The Rockefeller University, New York, NY, USA.

${ }^{4}$ Structural Biology Resource Center, The Rockefeller University, New York, NY 10065, USA

${ }^{5}$ Institute for Research in Biomedicine, Università della Svizzera italiana, Bellinzona, Switzerland.

${ }^{6}$ Howard Hughes Medical Institute, The Rockefeller University, New York, NY, USA.

$\dagger$ Equal contributions

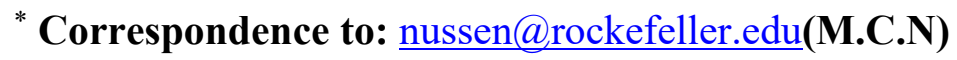


Abstract: SARS-CoV-2 primarily infects cells at mucosal surfaces. Serum neutralizing antibody responses are variable and generally low in individuals that suffer mild forms of the illness. Although potent IgG antibodies can neutralize the virus, less is known about secretory antibodies such as IgA that might impact the initial viral spread and transmissibility from the mucosa. Here we characterize the IgA response to SARS-CoV-2 in a cohort of 149 individuals. IgA responses in plasma generally correlate with $\operatorname{IgG}$ responses and clones of $\operatorname{IgM}, \operatorname{IgG}$ and $\operatorname{IgA}$ producing B cells that are derived from common progenitors are evident. Plasma IgA monomers are 2-fold less potent than IgG equivalents. However, IgA dimers, the primary form in the nasopharynx, are on average 15 times more potent than IgA monomers. Thus, secretory IgA responses may be particularly valuable for protection against SARS-CoV-2 and for vaccine efficacy.

\section{Introduction}

SARS-CoV-2 encodes a trimeric spike surface protein (S) which mediates entry into host cells $(1,2)$. The virus initially infects epithelial cells in the nasopharynx when the receptor binding domain (RBD) of S interacts with angiotensin converting enzyme-2 (ACE-2) receptor (3- 6 ). SARS-CoV-2 may subsequently spread to other epithelial cells expressing ACE-2 in the lung and gut. These tissues are rich in lymphoid cells that are organized into nasopharynx associated and gut associated lymphoid tissues (NALT and GALT respectively). Vaccines delivered by inhalation to specifically target these tissues appear to be more effective against SARS-CoV-2 (7). Among other specializations, NALT and GALT produce large quantities of IgA antibodies. These antibodies exist as monomers in circulation where they make up $15 \%$ of the serum antibody pool. However, $\operatorname{IgA}$ is found in higher concentrations in secretions where it exists predominantly as a dimer covalently linked by $\mathrm{J}$ chain $(8-10)$. 
Although most individuals produce antibodies in response to SARS-CoV-2 infection, the neutralizing response is highly variable with as many as 30\% of the population showing levels of neutralizing activity below 1:50 in pseudovirus assays $(11,12)$. Neutralization is associated with prolonged infection and RBD binding activity as measured by ELISA (11-13). IgG antibody cloning experiments from recovered individuals have revealed that neutralizing antibodies target several distinct non-overlapping epitopes on the $\operatorname{RBD}(11,14-18)$. Some of these antibodies are potently neutralizing and can prevent or treat infection in animal models (15-19).

Consistent with the fact that SARS CoV-2 initially infects in the nasopharynx, IgA antibodies that bind to SARS-CoV-2 are produced rapidly after infection and remain elevated in the plasma for at least 40 days after the onset of symptoms (20-23). IgA antibodies bind to the RBD and can neutralize SARS-CoV-2 (20-22). However, the precise contribution and molecular nature of the IgA response to SARS-CoV-2 has not been reported to date. Here we examine a cohort of 149 convalescent individuals with measurable plasma neutralizing activity for the contribution of IgA to anti-SARS-CoV-2 antibody responses. Cloning IgA antibodies from single B cells reveals that the neutralizing activity of monomeric IgA is generally lower than corresponding IgGs but dimeric IgAs are on average 15-fold more potent than their monomeric counterparts.

\section{Results}

\section{Plasma anti-SARS-CoV-2 RBD IgA}

IgM, IgG and IgA account for 5\%,80\% and 15\% of the antibodies in plasma, respectively. IgG responses to RBD are strongly correlated with neutralizing activity $(11,13-17,24-28)$. To 
examine the contribution of IgA to the anti-SARS-CoV-2 RBD response we tested plasma samples for binding to the RBD by a validated ELISA. A positive control sample (COV-21) was included for normalization of the area under the curve (AUC) and 8 independent healthy donor samples were included as negative controls (Fig. 1A, (11)). Whereas $78 \%$ and $15 \%$ of the individuals in this cohort showed IgG and IgM anti-RBD levels that were at least 2 standard deviations above control, only $33 \%$ did so for IgA (Fig. 1A and B, (11)). Thus, in individuals studied on average 40 days after infection the circulating levels of anti-RBD IgA is more modest than $\mathrm{IgG}$ and higher than IgM.

Anti-RBD IgA titers were correlated with duration and severity of symptoms but not timing of sample collection relative to onset (Fig. 1C, and fig.S1A, B). Similar to IgG, females had lower levels of $\operatorname{IgA}$ than males and hospitalized individuals showed higher anti-RBD IgA titers than those with milder symptoms, but there was no correlation with age (Fig. 1D and E, fig. S1C). Of note, individuals that suffered gastrointestinal symptoms showed significantly higher plasma anti-RBD IgA but not IgG titers (Fig. 1F and fig. S1D).

\section{Neutralization activity of purified IgG and IgA}

To compare the neutralizing activity of plasma $\operatorname{IgA}$ to $\operatorname{IgG}$ directly we purified the 2 isotypes from the plasma of all 99 individuals in our cohort that showed measurable plasma neutralizing activity and tested the two isotypes in HIV-1 based SARS-CoV-2 pseudovirus neutralization assays (11). The activity of both isotypes was directly correlated with anti-RBD binding titers and overall plasma neutralizing activity (Fig. 2A-D). In addition, there was good correlation between the neutralizing activity of IgG and IgA in a given individual (Fig. 2E). However, 
potency of each of the 2 isotypes varied by as much as 2 orders of magnitude between individuals (Fig. 2F). Purified IgG was generally more potent than IgA in neutralizing SARSCoV-2 pseudovirus in vitro. The geometric mean $\mathrm{IC}_{50}$ for $\mathrm{IgG}$ was $384 \mathrm{nM}$ vs. $709 \mathrm{nM}$ for IgA $(P<0.0001$, Fig. 2F). Nevertheless, IgAs were more potent than IgGs in $25 \%$ of the individuals tested (fig. S2A). The 2 isotypes also differed in that the overall potency of purified $\operatorname{IgG}$ was correlated with symptom severity and was higher in hospitalized individuals, but purified IgA was not (Fig. 2G and fig. S2B- D). Finally, the potency of the purified IgA was greater in individuals that suffered from gastrointestinal symptoms, but IgG was not (Fig. 2H and fig. S2E).

\section{Monoclonal anti-SARS-CoV-2 IgM and IgA antibodies}

To determine the nature of the IgM and IgA anti-RBD antibodies elicited by SARS-CoV-2 infection we used flow cytometry to purify single B lymphocytes that bind to RBD and cloned their antibodies. We obtained $109 \operatorname{IgM}$ and $74 \operatorname{IgA}(64 \operatorname{IgA} 1$ and $10 \operatorname{IgA} 2)$ matched Ig heavy and light chain sequences by reverse transcription and subsequent isotype specific PCR from 3 convalescent individuals (Fig. 3A, B). As reported for IgG antibodies $(11,14,17,26,29)$, the overall number of mutations was generally low when compared to antibodies obtained from individuals suffering from chronic infections such as Hepatitis-B or HIV-1 (30, 31) (fig. S3A, B). However, the number of $\mathrm{V}$ gene nucleotide mutations in IgM and IgA heavy and light chains varied between individuals. For example, in donor COV21 the number of IgM and IgA heavy chain mutations was similar. In contrast, IgM heavy and light chain nucleotide mutations were significantly greater than IgA mutations in COV47 (fig. S3B). CDR3 length was significantly shorter for IgM than IgA and IgG antibodies and hydrophobicity was slightly higher for IgM over control but not for IgA and IgG (figs. S4 and S5). Compared to the normal human antibody 
repertoire, several IgA and IgM VH genes were over-represented including VH3-53 which can make key contacts with the RBD through germline encoded CDRH1 and CDRH2 $(11,32,33)$ (fig. S6). individuals examined. Overall $66.2 \%$ and $66.1 \%$ of all the $\operatorname{IgA}$ and $\operatorname{IgM}$ sequences examined were members of expanded clones (Fig. 3A, B and table S1). Nearly identical sequences were shared among the 3 isotypes in clones found in all 3 individuals indicating that switch recombination occurred during B cell clonal expansion in response to SARS-CoV-2 (Fig.3B). In total 11 out of 55 antigen-specific B cell clones in circulation belonged to expanded clones that contained members expressing different constant regions (Fig. 3C and tables S1 and S2). When compared directly, the neutralizing activity of antibodies that were members of B cell clones producing IgA or IgG varied and did not correlate with one or the other isotype (table S3).

To examine the binding properties of the anti-SARS-CoV-2 monoclonals we expressed 46 IgMs and $35 \mathrm{IgAs}$ (table S4). IgM variable regions were produced on an IgG1 backbone to facilitate expression and purification. IgAs were expressed as native IgA1 or IgA2 monomers. ELISA assays on RBD showed that $100 \%$ and $91.3 \%$ of the $\operatorname{IgA}$ and $\operatorname{IgM}$ antibodies bound to the RBD with an average half-maximal effective concentration of $52.8 \mathrm{ng} / \mathrm{ml}$ and $101.6 \mathrm{ng} / \mathrm{ml}$ respectively (fig. S7A and table S5).

To determine neutralizing activity of the $\operatorname{IgM}$ and $\operatorname{IgA}$ antibodies we tested them against an HIV1 based SARS-CoV-2 pseudovirus as IgGs and native IgA monomers respectively. Among the 
42 RBD binding IgM antibodies tested we found 10 that neutralized the virus in the $\mathrm{ng} / \mathrm{ml} \mathrm{range}$ with geometric mean half-maximal inhibitory concentrations $\left(\mathrm{IC}_{50}\right)$ of 114.0 nanograms per milliliter (Fig. 4A and fig. S7B, table S5). In contrast, 32 out of 35 RBD binding IgA antibodies tested neutralized the virus in the $\mathrm{ng} / \mathrm{ml}$ range with geometric mean half-maximal inhibitory concentrations $\left(\mathrm{IC}_{50}\right)$ of 53.6 nanograms per milliliter (Fig. 4A and fig. S7B, table S5). Thus, IgM antibodies expressed as monomeric IgGs show lower neutralizing activity than either native IgA or IgG monomers (Fig. 4A).

\section{Dimeric anti- SARS-CoV-2 IgA is more potent than monomeric IgA}

To determine whether these IgAs targeted the same epitopes as previously characterized IgGs we performed bilayer interferometry experiments in which a preformed antibody-RBD complex consisting of C144-RBD, or C121-RBD or C135-RBD or CR3022-RBD (Fig. 4B) was exposed to a monomeric IgA monoclonal. C144 and C121 recognize the ACE-2 interaction domain of the RBD, C135 and CR3022 neutralize without interfering with ACE-2 binding (Fig. 4C) (11, 32, 34). Two of the IgA's were in the C144 category, 5 were similar to C121, and 2 resembled C135 (Fig. 4C and fig. S9). Thus, RBD recognition by neutralizing IgA is similar to IgG.

Mucosal IgA exists predominantly as a dimer. To examine the neutralizing activity of IgA dimers we co-expressed 8 IgA1s and 1 IgA2 with J chain to produce mixtures of monomers and dimers that were purified by size exclusion chromatography (fig. S8). When compared in pseudovirus neutralization assays, 8 out of $9 \operatorname{IgA}$ dimers were more potent than the corresponding monomers with differences in activity ranging from 3.8 to 113 -fold (Fig. 4D, fig. S10A and table S6). The relative increase in neutralizing activity between monomer and dimer 
was inversely correlated with the neutralizing activity of the monomer in this assay (fig. S10B. equivalent activity as a monomer and dimer, C408, one of the least potent antibodies, was 113fold more potent as a dimer (fig. S10B).

IgA monomers and dimers were also compared in SARS-CoV-2 microneutralization assays. in the pseudovirus neutralization assay (fig. S10C. $\mathrm{IC}_{50}: r=0.84, P<0.0001 ; \mathrm{IC}_{90}: r=0.91$, $P<0.0001)$. On average, there was a 15 -fold geometric mean increase in activity for the dimer over the monomer against SARS-CoV-2 and less variability in the degree of enhancement in microneutralization compared to pseudovirus assays (Fig. 4D, fig. S10D and E, and table S6). Thus, dimeric IgA is far more potent than monomeric IgA against SARS-CoV-2 (Fig. 4D).

\section{Discussion}

Neutralizing antibody titers are the best correlates of protection in most vaccines (35). Among antibody isotypes, secretory $\operatorname{IgA}$ which is found at mucosal surfaces, plays a crucial role in protecting against pathogens that target these surfaces (36). We find that serum IgA responses to SARS-CoV-2 correlate with IgG responses. Although the monomeric form of IgA found in serum is on average 2-fold less potent than $\operatorname{IgG}$, the dimeric secretory form of $\operatorname{IgA}$ found in mucosa is over one log more potent than the monomer against authentic SARS-CoV-2 which makes it a far more potent neutralizer than IgG. 
The increased potency of the dimeric form of IgA suggests that crosslinking the S protein on the viral surface enhances neutralizing activity either directly or simply through increased apparent affinity. This observation is consistent with the finding that monovalent Fab fragments of serum IgG antibodies are far less potent than the intact antibody (32). Whether this effect is due to inter- or intra-spike crosslinking is not known, but it indicates that antibodies or drugs designed to block entry by binding to the RBD could be made more potent by increasing their valency. targeted by SARS-CoV-2. Thus, even vaccines that elicit modest neutralizing activity in serum particularly effective preventing SARS-CoV-2 infection (7).

\section{Reference and notes} Glycoprotein. Cell 181, 281-292 e286 (2020).

2. P. Zhou et al., A pneumonia outbreak associated with a new coronavirus of probable bat origin. Nature 579, 270-273 (2020).

3. M. Hoffmann et al., SARS-CoV-2 Cell Entry Depends on ACE2 and TMPRSS2 and Is Blocked by a Clinically Proven Protease Inhibitor. Cell 181, 271-280 e278 (2020). 
4. R. Lu et al., Genomic characterisation and epidemiology of 2019 novel coronavirus: implications for virus origins and receptor binding. Lancet 395, 565-574 (2020).

5. D. Wrapp et al., Cryo-EM structure of the 2019-nCoV spike in the prefusion conformation. Science 367, 1260-1263 (2020).

6. J. Lan et al., Structure of the SARS-CoV-2 spike receptor-binding domain bound to the ACE2 receptor. Nature 581, 215-220 (2020).

7. A. O. Hassan et al., A single-dose intranasal ChAd vaccine protects upper and lower respiratory tracts against SARS-CoV-2. Cell, (2020).

8. B. J. Underdown, J. M. Schiff, Immunoglobulin A: strategic defense initiative at the mucosal surface. Annu Rev Immunol 4, 389-417 (1986).

9. M. E. Koshland, The coming of age of the immunoglobulin J chain. Annu Rev Immunol 3, 425-453 (1985).

10. O. Pabst, New concepts in the generation and functions of IgA. Nat Rev Immunol 12, $821-832$ (2012).

11. D. F. Robbiani et al., Convergent antibody responses to SARS-CoV-2 in convalescent individuals. Nature, (2020).

12. F. Wu et al., Evaluating the Association of Clinical Characteristics With Neutralizing Antibody Levels in Patients Who Have Recovered From Mild COVID-19 in Shanghai, China. JAMA Intern Med, (2020).

13. B. Ju et al., Human neutralizing antibodies elicited by SARS-CoV-2 infection. Nature, (2020).

14. P. J. M. Brouwer et al., Potent neutralizing antibodies from COVID-19 patients define multiple targets of vulnerability. Science, (2020). 
15. L. Liu et al., Potent neutralizing antibodies directed to multiple epitopes on SARS-CoV-2 spike. Nature, (2020).

16. Y. Wu et al., A noncompeting pair of human neutralizing antibodies block COVID-19 virus binding to its receptor ACE2. Science 368, 1274-1278 (2020).

17. T. F. Rogers et al., Isolation of potent SARS-CoV-2 neutralizing antibodies and protection from disease in a small animal model. Science, (2020).

18. S. J. Zost et al., Potently neutralizing and protective human antibodies against SARSCoV-2. Nature, (2020).

19. A. Baum et al., REGN-COV2 antibody cocktail prevents and treats SARS-CoV-2 infection in rhesus macaques and hamsters. bioRxiv, 2020.2008.2002.233320 (2020).

20. H. Ma et al., Serum IgA, IgM, and IgG responses in COVID-19. Cell Mol Immunol 17, 773-775 (2020).

21. D. Sterlin et al., IgA dominates the early neutralizing antibody response to SARS-CoV-2. medRxiv, 2020.2006.2010.20126532 (2020).

22. H. Q. Yu et al., Distinct features of SARS-CoV-2-specific IgA response in COVID-19 patients. Eur Respir J, (2020).

23. J. Seow et al., Longitudinal evaluation and decline of antibody responses in SARS-CoV2 infection. medRxiv, 2020.2007.2009.20148429 (2020).

24. X. Chi et al., A neutralizing human antibody binds to the N-terminal domain of the Spike protein of SARS-CoV-2. Science, (2020).

25. Y. Cao et al., Potent Neutralizing Antibodies against SARS-CoV-2 Identified by HighThroughput Single-Cell Sequencing of Convalescent Patients' B Cells. Cell 182, 73-84 e16 (2020) 
26. C. Kreer et al., Longitudinal Isolation of Potent Near-Germline SARS-CoV-2Neutralizing Antibodies from COVID-19 Patients. Cell, (2020).

27. F. Schmidt et al., Measuring SARS-CoV-2 neutralizing antibody activity using pseudotyped and chimeric viruses. J Exp Med 217, (2020).

28. R. Shi et al., A human neutralizing antibody targets the receptor-binding site of SARSCoV-2. Nature, (2020).

29. E. Seydoux et al., Analysis of a SARS-CoV-2-Infected Individual Reveals Development of Potent Neutralizing Antibodies with Limited Somatic Mutation. Immunity 53, 98-105

31. Q. Wang et al., A Combination of Human Broadly Neutralizing Antibodies against e105 (2020)

30. J. F. Scheid et al., Broad diversity of neutralizing antibodies isolated from memory B Microbe, (2020).

32. C. O. Barnes et al., Structures of Human Antibodies Bound to SARS-CoV-2 Spike Reveal Common Epitopes and Recurrent Features of Antibodies. Cell, (2020).

33. M. Yuan et al., Structural basis of a shared antibody response to SARS-CoV-2. Science, (2020).

34. M. Yuan et al., A highly conserved cryptic epitope in the receptor binding domains of SARS-CoV-2 and SARS-CoV. Science 368, 630-633 (2020).

35. S. A. Plotkin, Correlates of protection induced by vaccination. Clin Vaccine Immunol 17, 1055-1065 (2010). 
36. K. Chen, G. Magri, E. K. Grasset, A. Cerutti, Rethinking mucosal antibody responses:

IgM, IgG and IgD join IgA. Nat Rev Immunol 20, 427-441 (2020).

37. A. Grifoni et al., Targets of T Cell Responses to SARS-CoV-2 Coronavirus in Humans with COVID-19 Disease and Unexposed Individuals. Cell 181, 1489-1501 e1415 (2020).

38. F. Amanat et al., A serological assay to detect SARS-CoV-2 seroconversion in humans. Nat Med 26, 1033-1036 (2020).

39. T. Tiller et al., Efficient generation of monoclonal antibodies from single human B cells by single cell RT-PCR and expression vector cloning. J Immunol Methods 329, 112-124 (2008).

40. L. von Boehmer et al., Sequencing and cloning of antigen-specific antibodies from mouse memory B cells. Nat Protoc 11, 1908-1923 (2016).

41. D. F. Robbiani et al., Recurrent Potent Human Neutralizing Antibodies to Zika Virus in Brazil and Mexico. Cell 169, 597-609 e511 (2017).

42. J. Ye, N. Ma, T. L. Madden, J. M. Ostell, IgBLAST: an immunoglobulin variable domain sequence analysis tool. Nucleic Acids Res 41, W34-40 (2013).

43. N. T. Gupta et al., Change-O: a toolkit for analyzing large-scale B cell immunoglobulin repertoire sequencing data. Bioinformatics 31, 3356-3358 (2015).

44. C. Soto et al., High frequency of shared clonotypes in human B cell receptor repertoires. Nature 566, 398-402 (2019).

45. Y. Guo, K. Chen, P. D. Kwong, L. Shapiro, Z. Sheng, cAb-Rep: A Database of Curated Antibody Repertoires for Exploring Antibody Diversity and Predicting Antibody Prevalence. Front Immunol 10, 2365 (2019). 
Acknowledgements: We thank all study participants who devoted time to our research; Drs.

Barry Coller and Sarah Schlesinger, the Rockefeller University Hospital Clinical Research

Support Office and nursing staff; Ivo Lorenz and the Tri-I TDI antibody team for help with BLI measurements. All members of the M.C.N. laboratory for helpful discussions, Maša Jankovic for laboratory support. Funding: This work was supported by NIH grant P01-AI138398-S1 and 2U1 9AI111825 to M.C.N. and C.M.R.; George Mason University Fast Grants to D.F.R. and C.M.R., 3 R01-AI091707-10S1 to C.M.R.; The G. Harold and Leila Y. Mathers Charitable Foundation to C.M.R.; European ATAC consortium (EC 101003650) to D.F.R. C.G. was supported by the Robert S. Wennett Post-Doctoral Fellowship, in part by the National Center for Advancing Translational Sciences (National Institutes of Health Clinical and Translational Science Award programme, grant UL1 TR001866) and by the Shapiro-Silverberg Fund for the Advancement of Translational Research. P.D.B. and M.C.N. are Howard Hughes Medical Institute Investigators.

Author contributions: Z.W., J.C.C.L., F.M., S.F. and M.C.N. conceived, designed and analyzed the experiments. Z.W., J.C.C.L., F.M., S.F., C.V., M.C., H.-H.H. L.N. and E.M. carried out all experiments. D.F.R., M. Caskey and C.G. designed clinical protocols. M.C., A.G. and D.O. produced antibodies. T.Y.O., and V.R. performed bioinformatic analysis. C.M.R., T.M. and P.D.B. helped designing the experiments. Z.W., J.C.C.L., F.M., S.F. and M.C.N. wrote the manuscript with input from all co-authors. Declaration of conflict: In connection with this work The Rockefeller University has filed a provisional patent application on which D.F.R. and M.C.N. are inventors. Data and materials availability: Data are provided in table S1, 2,4 . The raw sequencing data associated with Fig. 3 has been deposited at Github (https://github.com/stratust/igpipeline). This study uses data from a database of human shared BCR clonotypes "https://cabrep.c2b2.columbia.edu/home/", and from 'cAb-Rep: A Database of 
321 Computer code to process the antibody sequences are available at GitHub

\section{Supplementary materials:}

Materials and Methods

Figs. S1 to S10

Tables S1 to S7

Reference (37-45) 
A

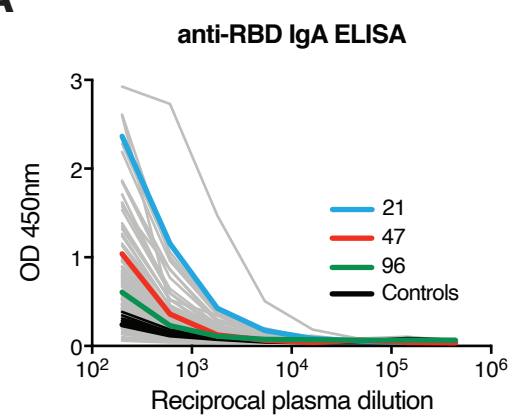

B

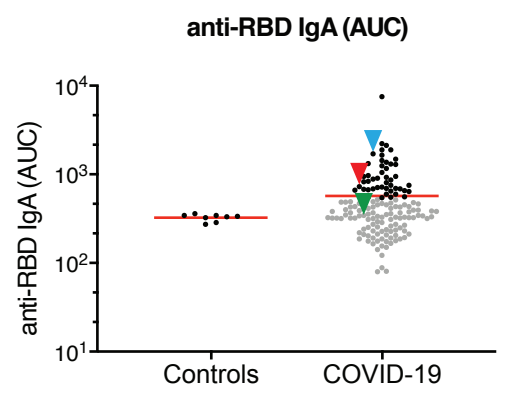

C

Sx severity - anti-RBD IgA

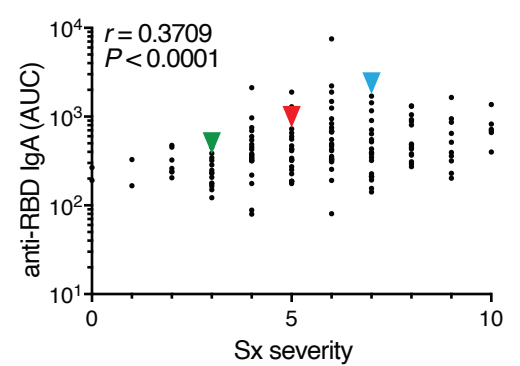

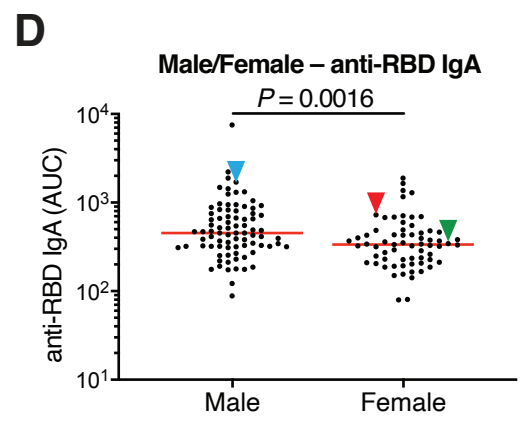

$\mathbf{E}$

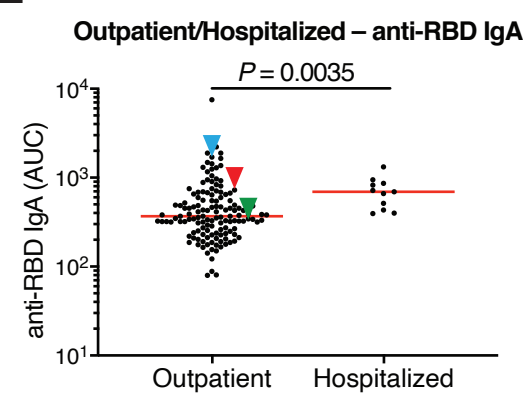

$\mathbf{F}$

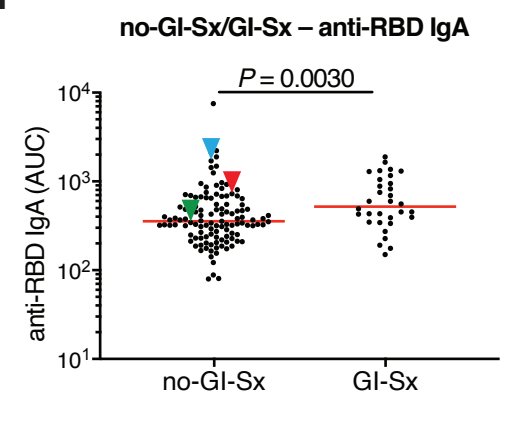

Fig. 1 Plasma IgA against SARS-CoV-2 RBD. (A) ELISAs measuring plasma IgA reactivity to RBD. Graph shows optical density units at $450 \mathrm{~nm}$ (OD, Y axis) and reciprocal plasma dilutions (X axis). Negative controls in black; individuals 21, 47, 96 in blue, red and green lines and arrowheads, respectively (11). (B) Graph shows normalized area under the curve (AUC) for 8 controls and each of 149 individuals in the cohort. Horizontal bar indicates mean values. Black dots indicate the individuals that are 2 STDV over the mean of controls. (C) Subjective Symptom (Sx) severity (X axis) is plotted against the normalized AUC for IgA binding to RBD (Y axis). $r$ 
$339=0.3709, P<0.0001$. (D) Normalized AUC of anti-RBD IgA ELISA for males $(\mathrm{n}=83)$ and

340 females $(\mathrm{n}=66) ; P=0.0016$. (E) Normalized AUC of anti-RBD IgA ELISA for outpatients

$341 \quad(\mathrm{n}=138)$ and hospitalized $(\mathrm{n}=11)$ individuals; $P=0.0035$. (F) Normalized AUC of anti-RBD IgA

342 ELISA for patients with gastrointestinal (GI) symptoms ( $\mathrm{n}=32)$ and without GI symptoms

$343 \quad(\mathrm{n}=117) ; P=0.0030$. The $r$ and $P$ values for the correlations in $(\mathrm{C})$ were determined by two-

344 tailed Spearman's. For (D-F) horizontal bars indicate median values. Statistical significance was

345 determined using two-tailed Mann-Whitney U test. 
A

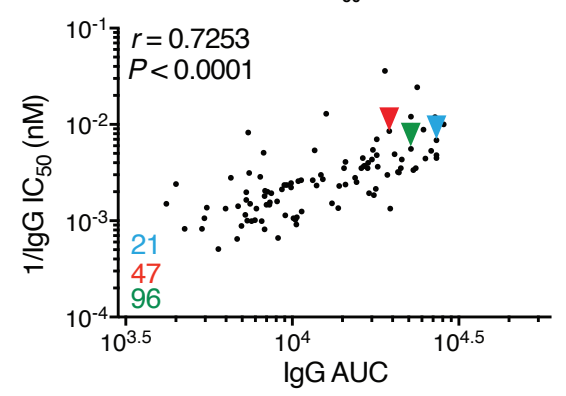

C Purfied IgG $\mathrm{IC}_{50}{ }^{-1}-$ plasma NT $_{50}$

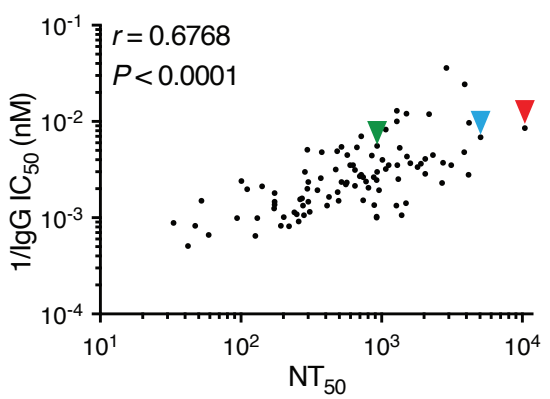

E Purified $\lg G \mathrm{IC}_{50}-$ Purified IgA IC 50

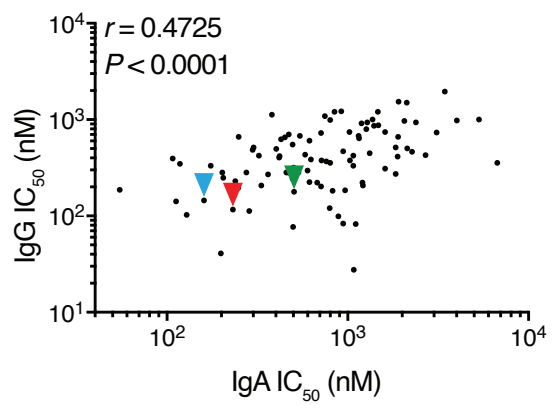

G

$$
\text { Purified IgG IC }{ }_{50}^{-1}-\text { Sx severity }
$$

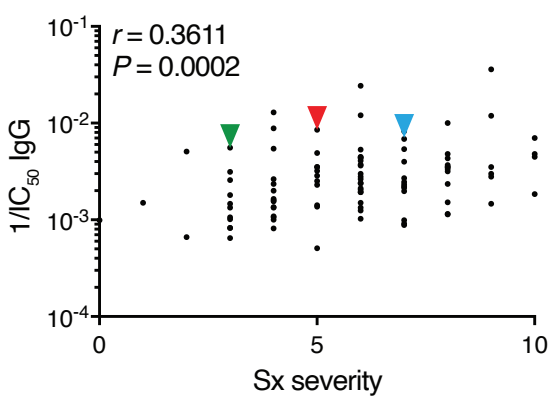

B Purified $\lg A \mathrm{IC}_{50}{ }^{-1}-\operatorname{IgA} \mathrm{AUC}$

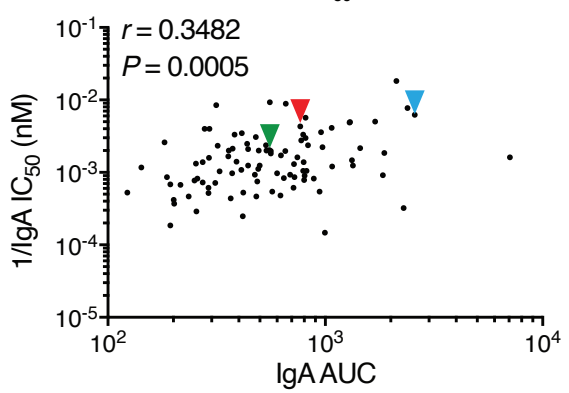

D Purified IgA $I C_{50}^{-1}-$ plasma NT $_{50}$

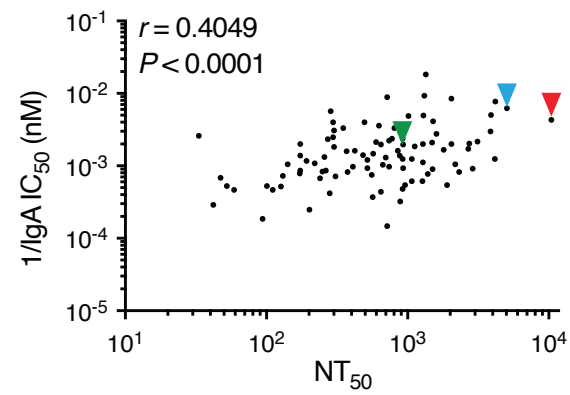

\section{$\mathbf{F}$}

Purified IgA/ Purified IgG - IC $C_{50}$

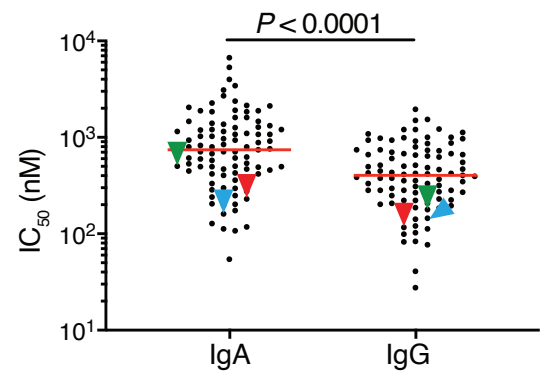

H
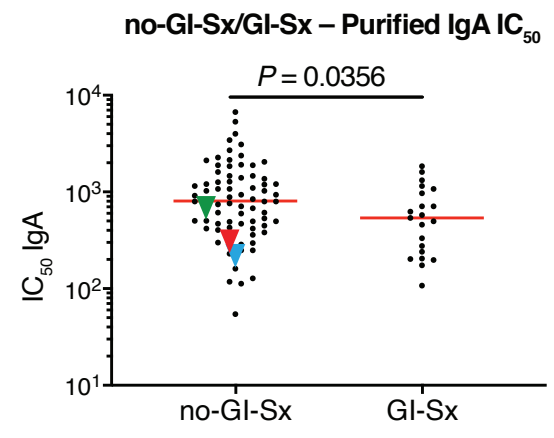

Fig. 2 SARS-CoV-2 pseudovirus neutralization by purified IgA and IgG. Neutralization 
HT1080 ${ }_{\text {ACE2 }} \mathrm{cl} .14$ cells $48 \mathrm{~h}$ after infection with nanoluc-expressing SARS-CoV-2 pseudovirus. (A) Normalized AUC for plasma IgG anti-RBD ELISA (X axis) plotted against purified IgG pseudovirus neutralization $1 / \mathrm{IC}_{50}$ values (Y axis). $r=0.7253, P<0.0001$. (B) Normalized AUC for plasma IgA ELISA ( $\mathrm{X}$ axis) plotted against purified IgA pseudovirus neutralization $1 / \mathrm{IC}_{50}$ values (Y axis). $r=0.3482, P=0.0005$. (C) Published plasma $\mathrm{NT}_{50}$ values (11) (X axis) plotted against purified $\mathrm{IgG}$ pseudovirus neutralization $1 / \mathrm{IC}_{50}$ values ( $\mathrm{Y}$ axis). $r=0.6768, P<$ 0.0001. (D) Published plasma NT50 values (11) (X axis) plotted against purified IgA pseudovirus neutralization $1 / \mathrm{IC}_{50}$ values (Y axis). $r=0.4049, P<0.0001$. (E) Purified IgA pseudovirus neutralization $\mathrm{IC}_{50}$ values ( $\mathrm{X}$ axis) plotted against purified $\mathrm{IgG}$ pseudovirus neutralization $\mathrm{IC}_{50}$ values. $r=0.4725, P<0.0001$. (F) Comparison of purified IgA and IgG pseudovirus neutralization $\mathrm{IC}_{50}$ values, $P<0.0001$. (G) Symptom severity plotted against purified $\mathrm{IgG}$ pseudovirus neutralization $1 / \mathrm{IC}_{50}$ values. $r=0.3611, P=0.0002$. $(\mathrm{H})$ Purified IgA pseudovirus neutralization $\mathrm{IC}_{50}$ values for patients with GI symptoms $(\mathrm{n}=21)$ and without GI symptoms $(\mathrm{n}=74) ; P=0.0356$. The $r$ and $p$ values in $(\mathrm{A}-\mathrm{E}, \mathrm{G})$ were determined by two-tailed Spearman's correlations. In ( $\mathrm{F}$ and $\mathrm{H}), p$ values were determined by two-tailed Mann-Whitney U-tests and horizontal bars indicate median values. 
A
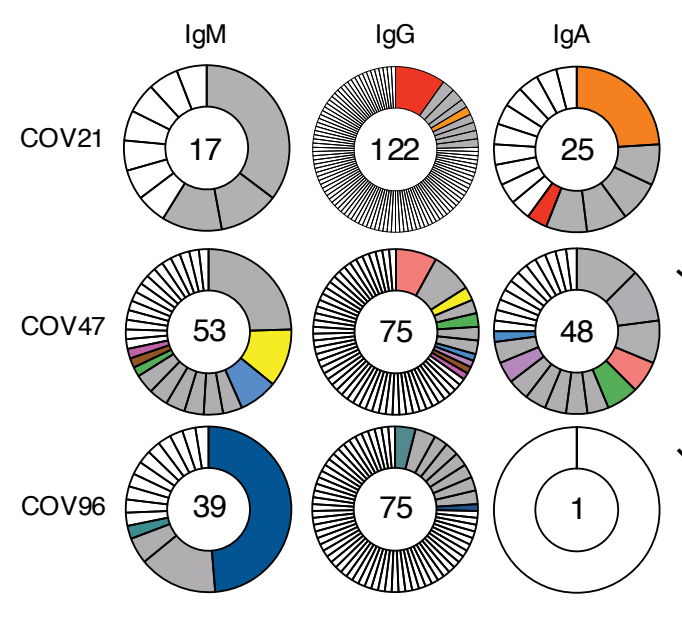

B

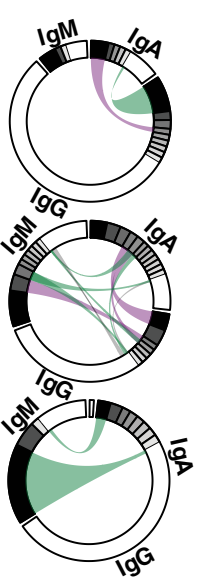

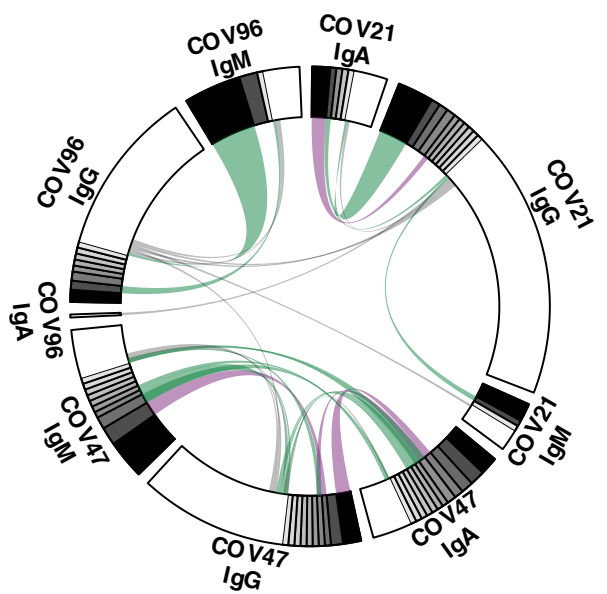

C

\begin{tabular}{|c|c|c|c|c|c|c|c|c|}
\hline & & \multicolumn{4}{|c|}{ HEAVY } & \multicolumn{3}{|c|}{ LIGHT } \\
\hline & & IGHV & IGHD & IGHJ & $\mathrm{CDRH} 3$ & IGLV & IGL & CDRL3 \\
\hline \multirow{12}{*}{ cov47 } & IGM & IGHV3-21*01 & IGHD4-23*01 & $\mathrm{IGHJ} 4 * 02$ & ARERGYHGGKTSPFL & IGLV6-57*02 & IGLJ $3 * 02$ & QSYDSSNYWV \\
\hline & IGG & IGHV3-21*01 & IGHD4-23*01 & $\mathrm{IGHJ} 4 * 02$ & ........... & IGLV6-57*02 & $\mathrm{IGLJ} 3 * 02$ & $\ldots \ldots \ldots$ \\
\hline & IGG & IGHV3-21*01 & IGHD4-23*01 & IGHJ4*02 & .........P... & IGLV6-57*02 & IGLJ $3 * 02$ & $\ldots \ldots \ldots$ \\
\hline & IGA & IGHV3-21*01 & IGHD4-23*01 & $\mathrm{IGHJ} 4 * 02$ & $\ldots \ldots Y \ldots$.... & IGLV6-57*02 & $\mathrm{IGLJ} 3 * 02$ & $\ldots \ldots \ldots$ \\
\hline & IGA & IGHV3-21*01 & IGHD4-23*01 & $\mathrm{IGHJ} 4 * 02$ & $\ldots \ldots Y \ldots P \ldots$ & IGLV6-57*02 & IGLJ $3 * 02$ & $\ldots \ldots \ldots$ \\
\hline & IGA & IGHV3-21*01 & IGHD4-23*01 & $\mathrm{IGHJ} 4 * 02$ & $\ldots \ldots Y \ldots$... & IGLV6- $57 * 02$ & IGLJ3*02 & $\ldots \ldots \ldots \ldots$ \\
\hline & IGM & IGHV4-59*01 & IGHD3-10*01 & $\mathrm{IGHJ} 4 * 02$ & ARYQLAPGSGSYYNWGGYPRESEYYFDY & IGLV2-11*01 & $\mathrm{IGLJ} 3 * 02$ & CSYAGSYTWV \\
\hline & IGM & IGHV4-59*01 & IGHD3-10*01 & $\mathrm{IGHJ} 4 * 02$ & n.m. & IGLV2-11*01 & $\mathrm{IGLJ} 3 * 02$ & $\ldots \ldots \ldots$ \\
\hline & IGM & IGHV4-59*01 & IGHD3 $-10 * 01$ & $\mathrm{IGHJ} 4 * 02$ & n........... & IGLV2-11*01 & $\mathrm{IGLJ} 3 * 02$ & $\ldots \ldots \ldots$ \\
\hline & IGM & IGHV4-59*01 & IGHD3-10*01 & IGHJ $4 * 02$ & 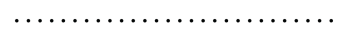 & IGLV2-11*01 & IGLJ $3 * 02$ & $\ldots \ldots \ldots$ \\
\hline & IGG & IGHV4-59*01 & IGHD3 $-10 * 01$ & $\mathrm{IGHJ} 4 * 02$ & n...................... & IGLV2-11*01 & $\mathrm{IGLJ} 3 * 02$ & $\ldots \ldots \ldots$ \\
\hline & IGA & IGHV4-59*01 & IGHD3-10*01 & $\mathrm{IGHJ} 4 * 02$ & 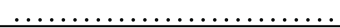 & IGLV2-11*01 & IGLJ3*02 & $\ldots \ldots \ldots$ \\
\hline
\end{tabular}

Fig. 3 Monoclonal anti-SARS-CoV-2 RBD IgM, IgG and IgA. (A) Clonal expansion of B indicates clones that are not shared. White indicates singlets that are not shared. The right side circos plots show the relationship between antibodies of different isotypes that share same IGH V(D)J and IGL VJ genes, and highly similar CDR3s. Purple, green and grey lines connect related 
378 clones, clones and singles, and singles to each other, respectively. (B) Circos plot shows

379 sequences from all 3 individuals with clonal relationships depicted as in (A). (C) Sample

380 sequence alignment for antibodies of different isotypes that display same IGH V(D)J and IGL VJ

381 genes and highly similar CDR3s. Amino acid differences in CDR3s to the reference sequence

382 (bold) are indicated in red, dashes indicate missing amino acids and dots represent identical

383 amino acids. 
A

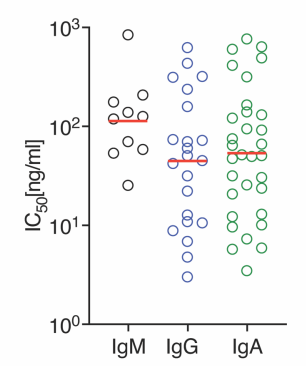

C
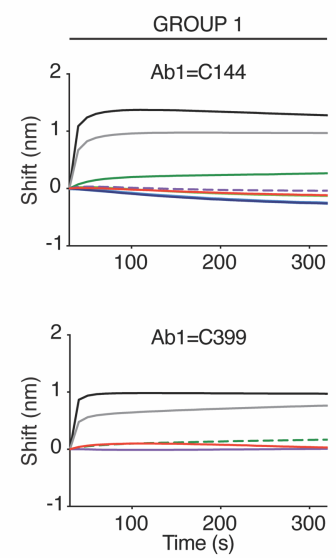

D

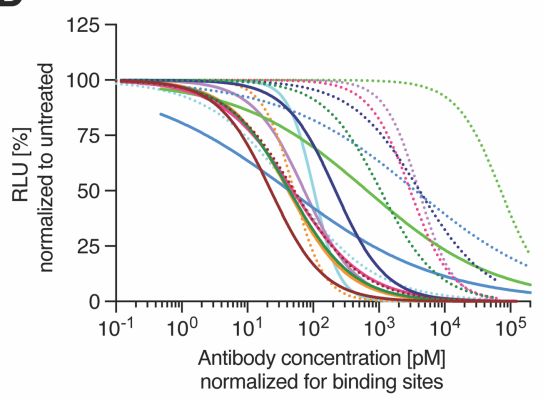

B
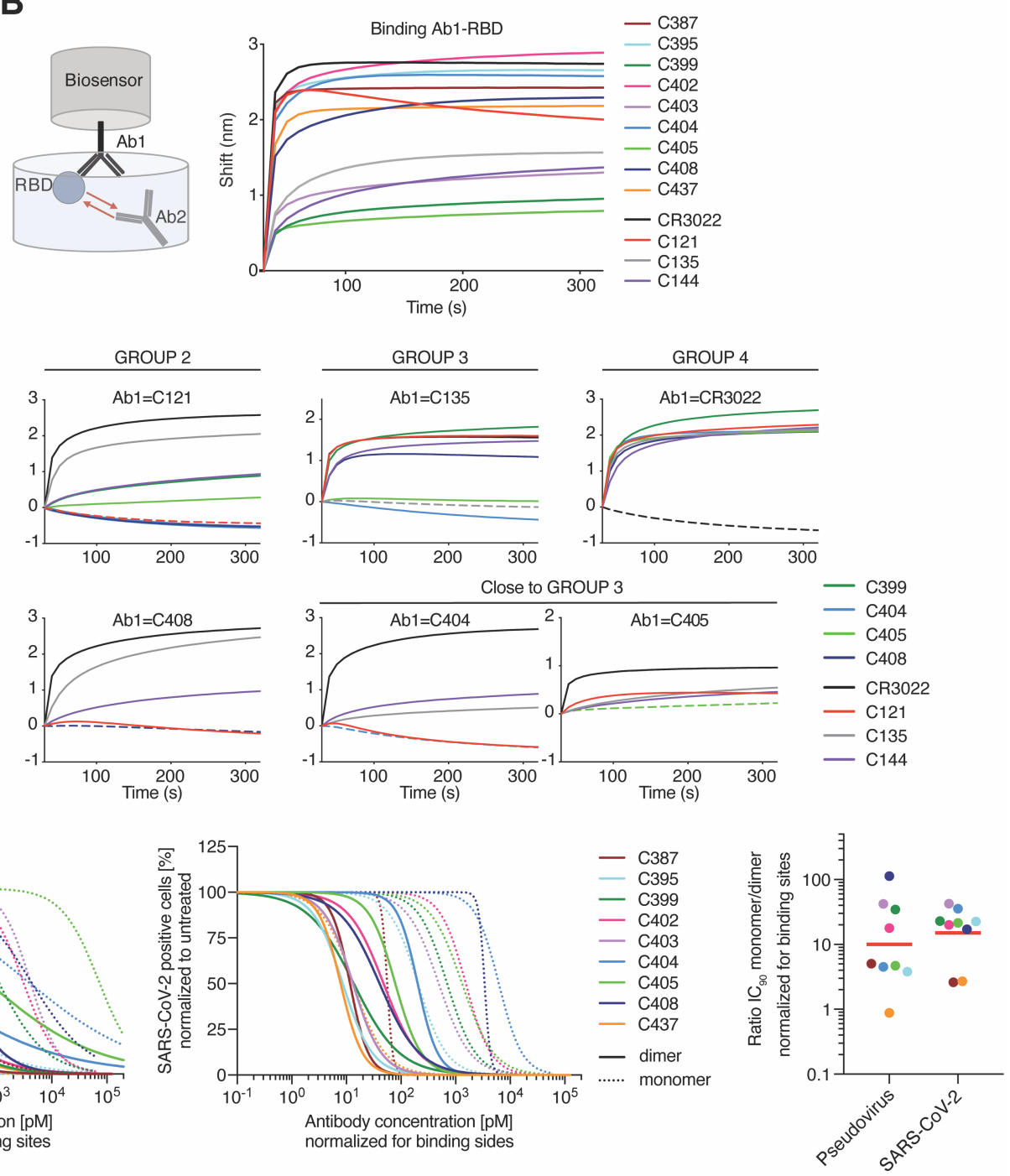

386

Fig. 4 IgA dimers neutralize SARS-CoV-2 more potently than monomers. (A) Pseudovirus

$\mathrm{IC}_{50}$ neutralization values for $\operatorname{IgA}$, and $\operatorname{IgM}$ monoclonals and published $\mathrm{IgG}$ monoclonals from the same individuals (11). Antibodies with $\mathrm{IC}_{50}$ less than $1000 \mathrm{ng} / \mathrm{ml}$ are shown. Red lines indicate geometric mean. (B) Diagrammatic representation of biolayer interferometry experiment (left panel). Binding of C387, C395, C399, C402, C403, C404, C405, C408, C437, CR3022, C121, C135, C144 to RBD (right panel). (C) Second antibody (Ab2) binding to preformed first antibody (Ab1)-RBD complexes. Dotted line denotes when Ab1 and Ab2 are the same, and Ab2 
394 is according to the colour-coding in $\mathrm{g}$. h, 1, Group 1 antibodies were tested. (D) The normalized

395 relative luminescence values for cell lysates of $293 \mathrm{~T}_{\mathrm{ACE} 2}$ cells after infection with SARS-CoV-2

396 pseudovirus (left panel) or normalized percentage of SARS-CoV-2 positive VeroE6 cells $48 \mathrm{~h}$

after infection with SARS-CoV-2 authentic virus (middle panel; values obtained in the absence

of antibody are plotted at $\mathrm{x}=0.1$ to be visible on log-scale) in the presence of increasing concentrations of monoclonal antibodies C387, C395, C399, C402, C403, C404, C405, C408, normalized data. Comparison of the ratio of $\mathrm{IC}_{90}$ values of monomer to dimers, normalized to number of antibody binding sites (right panel). 


\section{Materials and Methods}

\section{Human Study participants}

Samples were obtained from 149 individuals under a study protocol approved by the Rockefeller University in New York from April 1 through May 8, 2020 as described in (11). All participants provided written informed consent before participation in the study and the study was conducted in accordance with Good Clinical Practice and clinical data collection. The study was performed in compliance with all relevant ethical regulations and the protocol was approved by the Institutional Review Board (IRB) of the Rockefeller University.

\section{Purification and quantification of IgA and IgG from plasma}

IgA and IgG were purified from samples with measurable neutralizing activity, against SARS-CoV-2-RBD (11). $300 \mu \mathrm{l}$ of plasma was diluted with PBS heat-inactivated $\left(56^{\circ} \mathrm{C}\right.$ for $\left.1 \mathrm{hr}\right)$ and incubated with peptide M/Agarose (Invivogen) or Protein G/Agarose (GE lifeSciences) overnight at $4{ }^{\circ} \mathrm{C}$. The suspension was transferred to chromatography columns and washed with 10 column volumes of $1 \mathrm{X}-\mathrm{PBS}$. IgA and IgG were then eluted with $1.5 \mathrm{ml}$ of $0.1 \mathrm{M}$ glycine $(\mathrm{pH}=3.0)$ and $\mathrm{pH}$ was immediately adjusted to 7.5 with $1 \mathrm{M}$ Tris $(\mathrm{pH}=8.0)$. 1X-PBS buffer exchange was achieved using Amicon ${ }^{\circledR}$ Ultra centrifugal filters (Merck Millipore) through a 30-kD membrane according to the manufacturer's instructions. IgA and IgG concentrations were determined by measurement of absorbance at 280nm using a NanoDrop (Thermo Scientific) instrument and samples were stored at $4^{\circ} \mathrm{C}$.

\section{ELISAs}

ELISAs to evaluate the IgG or IgA binding to SARS-CoV-2 RBD were performed as previously described using a validated assay $(37,38)$. High binding 96 half well plates (Corning \#3690) were coated with $50 \mu \mathrm{L}$ per well of a $1 \mu \mathrm{g} / \mathrm{mL}$ protein solution in PBS overnight at $4{ }^{\circ} \mathrm{C}$. Plates were washed 6 times with washing buffer $(1 \times \mathrm{PBS}$ with 0.05\% Tween 20 (Sigma-Aldrich)) and incubated with $170 \mu \mathrm{L}$ blocking buffer per well (1xPBS with $2 \%$ BSA and 0.05\% Tween20 (Sigma) for 1 hour at room temperature (RT). Immediately after blocking, monoclonal antibodies or plasma samples were added in PBS and incubated for $1 \mathrm{hr}$ at RT. Plasma samples were assayed at a 1:200 starting dilution and seven additional 3-fold serial dilutions. Monoclonal antibodies were tested at $10 \mu \mathrm{g} / \mathrm{ml}$ starting concentration and 10 additional 4-fold serial dilutions. Plates were washed 6 times with washing buffer and then incubated with anti-human IgG (Jackson Immuno Research 109-036-088) or anti-human IgA (Sigma A0295) 
secondary antibody conjugated to horseradish peroxidase (HRP) in blocking buffer at 1:5000 or 1:3000 dilution respectively. Plates were developed by addition of the HRP substrate, TMB (ThermoFisher) for 10 minutes (plasma samples) or 4 minutes (monoclonal antibodies), then the developing reaction was stopped by adding $50 \mu 11 \mathrm{M}$ $\mathrm{H}_{2} \mathrm{SO}_{4}$. ODs were measured at $450 \mathrm{~nm}$ in a microplate reader (FluoStar Omega, BMG Labtech). For plasma samples, a positive control (plasma from patient COV21, diluted 200-fold in PBS) and negative control historical plasma samples was added in duplicate to every assay plate for validation. The average of its signal was used for normalization of all the other values on the same plate with Excel software prior to calculating the area under the curve using Prism 8 (GraphPad).

\section{Cell lines}

HT1080 Ace2 cl.14 cells (27), 293T Ace2 cells (11) and VeroE6 kidney epithelial cells were cultured in Dulbecco's modified Eagle medium (DMEM) supplemented with $10 \% \mathrm{FCS}$ at $37{ }^{\circ} \mathrm{C}$ and $5 \% \mathrm{CO}_{2}$. In addition, medium for Ace2-overexpressing cell lines contained $5 \mu \mathrm{g} / \mathrm{ml}$ blasticidin and medium for VeroE6 cells was supplemented with 1 $\%$ nonessential amino acids. All cell lines have been tested negative for contamination with mycoplasma and parental cell lines were obtained from the ATCC.

\section{Pseudotyped virus neutralization assay}

SARS-CoV-2 pseudotyped particles were produced by co-transfection of pSARS-CoV-2 $\mathrm{S}_{\text {trunc }}$ and pNL4-3 $\Delta$ Envnanoluc in 293T cells $(11,27)$. Four-fold serially diluted purified plasma IgG/IgA from COVID-19 convalescent individuals and healthy donors or monoclonal antibodies were incubated with the SARS-CoV-2 pseudotyped virus for 1 hour at $37^{\circ} \mathrm{C}$. Subsequently, the mixture was incubated with Ace2-expressing cells for 48 hours. HT1080 Ace2 cl. 14 cells (27) were used for plasma-derived $\operatorname{IgG} / \operatorname{IgA}$ and $293 \mathrm{~T}_{\text {Ace2 }}$ cells (11) for monoclonal antibodies. Following incubation, cells were washed twice with PBS and lysed with Luciferase Cell Culture Lysis 5x reagent (Promega). Nanoluc Luciferase activity in lysates was measured using the Nano-Glo Luciferase Assay System (Promega) with a GloMax Natigator Microplate Luminometer (Promega). Relative luminescence units obtained were normalized to those derived from cells infected with SARS-CoV-2 pseudotyped virus in the absence of plasma-derived or monoclonal antibodies. The half-maximal and $90 \%$ inhibitory concentrations for purified plasma IgG or IgA or monoclonal antibodies (IC50 and IC90) were determined using 4-parameter nonlinear regression (GraphPad Prism). 


\section{Antibody sequencing, cloning and expression}

Single B cells were isolated from COV21, COV47 and COV96 patients as previously described(11). Briefly, RNA from single cells was reverse-transcribed (SuperScript III Reverse Transcriptase, Invitrogen, 18080-044) using random primers (Invitrogen, 48190011) and followed by nested PCR amplifications and sequencing using the performed with MacVector. Antibody cloning from PCR products was performed as previously described by sequencing and ligation-independent cloning into antibody expression vectors (Ig $\gamma 1-$, IGк-, IG $\lambda$-, Ig $\alpha 1$ and $\operatorname{Ig} \alpha 2)$ as IgA2). J chain plasmid was a gift from Susan Zolla-Pazner. Recombinant monoclonal antibodies were produced and purified as previously described $(39,41)$. Briefly, monoclonal antibodies were produced by transient co-transfection of 293-F cells with human heavy chain and light chain antibody expression plasmids using polyethylenimine (PEI) (Sigma-Aldrich, catalog \#408727). Seven days after transfection, supernatants were harvested, clarified by centrifugation and subsequently incubated with Peptide M(Invivogen)/Protein G-coupled sepharose beads (Invivogen, catalog\# gel-pdm-5; GE healthcare, 17-0618-05) overnight at $4^{\circ} \mathrm{C}$. For dimers, antibodies were produced by transient transfection of Expi293F cells with heavy chain, light chain and J chain expression plasmids at a 1:1:1 ratio. After five days, antibodies were harvested, filtered, incubated with Peptide M overnight and eluted.

\section{Separation of Dimeric IgA from its Monomeric Form by Size Exclusion Chromatography}

A Pre-packed HiLoad ${ }^{\mathrm{TM}}$ 16/60 Superdex ${ }^{\mathrm{TM}} 200$ pg (Cytiva, catalog \#28989335) on the NGCTM Quest 10 Plus Chromatography System by Bio-Rad was calibrated at room temperature using the HMW Gel Filtration Calibration Kit (Cytiva, catalog \#28403842) and IgG. After equilibration of the column with PBS, each concentrated IgA preparation was applied onto the column using a $1 \mathrm{ml}$-loop at a flow rate of $0.5 \mathrm{ml} / \mathrm{min}$. Dimers of IgA1 or IgA2 were separated from monomers upon an isocratic elution with $70 \mathrm{ml}$ of PBS. The fractions were pooled, concentrated and evaluated by SDS-PAGE using 4-12\% Bis-Tris Novex gels (GenScript catalog \#M00652) under reducing and non-reducing conditions followed by a Coomassie blue staining (Expedeon, catalog \#ISB1L). 


\section{Microneutralization assay with authentic SARS-CoV-2.}

Production of SARS-CoV-2 virus was performed as previously described (11). This assay was performed as described previously $(11,42)$. VeroE6 cells were seeded at $1 \times 10^{4}$ cells/well into 96 -well plates on the day before infection. IgA monomers and dimers were serially diluted (4-fold) in BA-1, consisting of medium 199 (Lonza, Inc.) supplemented with $1 \%$ bovine serum albumin (BSA) and 1x penicillin/streptomycin. The diluted samples were mixed with a constant amount of SARS-CoV-2 and incubated for $1 \mathrm{hr}$ at $37^{\circ} \mathrm{C}$. The antibody-virus-mix was then directly applied to VeroE6 cells (MOI of $\sim 0.1 \mathrm{PFU} /$ cell; $\mathrm{n}=3$ ) and incubated for $22 \mathrm{~h}$ at $37^{\circ} \mathrm{C}$. Cells were subsequently fixed by adding an equal volume of $7 \%$ formaldehyde to the wells, followed by permeabilization with $0.1 \%$ Triton X-100 for $10 \mathrm{~min}$. After extensive washing, cells were incubated for $1 \mathrm{hr}$ at $37^{\circ} \mathrm{C}$ with blocking solution of 5\% goat serum in PBS (catalog no. 005-000-121; Jackson ImmunoResearch). A rabbit polyclonal anti-SARSCoV-2 nucleocapsid antibody (catalog no. GTX135357; GeneTex) was added to the cells at 1:1,000 dilution in blocking solution and incubated at $4{ }^{\circ} \mathrm{C}$ overnight. Goat anti-rabbit AlexaFluor 594 (catalog no. A-11012; Life Technologies) was used as a secondary antibody at a dilution of 1:2,000. Nuclei were stained with Hoechst 33342 (catalog no. 62249; Thermo Scientific) at a 1:1,000 dilution. Images were acquired with a fluorescence microscope and analyzed using ImageXpress Micro XLS (Molecular Devices, Sunnyvale, CA). All experiments involving SARS-CoV-2 were performed in a biosafety level 3 laboratory.

\section{Biolayer interferometry}

BLI assays were performed on the Octet Red instrument (ForteBio) at $30^{\circ} \mathrm{C}$ with shaking at 1,000 r.p.m. Epitope binding assays were performed with protein A biosensor (ForteBio 18-5010), following the manufacturer's protocol “classical sandwich assay". (1) Sensor check: sensors immersed $30 \mathrm{sec}$ in buffer alone (buffer ForteBio 18-1105). (2) Capture 1st Ab: sensors immersed 10 min with Ab1 at $40 \mu \mathrm{g} / \mathrm{mL}$. (3) Baseline: sensors immersed 30 sec in buffer alone. (4) Blocking: sensors immersed 5 min with IgG isotype control at $50 \mu \mathrm{g} / \mathrm{mL}$. (6) Antigen association: sensors immersed 5 min with RBD at $100 \mu \mathrm{g} / \mathrm{mL}$. (7) Baseline: sensors immersed $30 \mathrm{sec}$ in buffer alone. (8) Association Ab2: sensors immersed 5 min with Ab2 at $40 \mu \mathrm{g} / \mathrm{mL}$. Curve fitting was performed using the Fortebio Octet Data analysis software (ForteBio).

\section{Computational analyses of antibody sequences}


Antibody sequences were trimmed based on quality and annotated using Igblastn v1.14.0[ref] with IMGT domain delineation system. Annotation was performed systematically using Change-O toolkit v.0.4.5(43). Heavy and light chains derived from the same cell were paired, and clonotypes were assigned based on their $\mathrm{V}$ and $\mathrm{J}$ genes using inhouse R and Perl scripts (Fig. 3 A and B). All scripts and the data used to process antibody sequences are publicly available on GitHub (https://github.com/stratust/igpipeline). Nucleotide somatic hypermutation and CDR3 length were determined using in-house R and Perl scripts. For somatic hypermutations, IGHV and IGLV nucleotide sequences were aligned against their closest germlines using Igblastn and the number of differences were considered nucleotide mutations. The average mutations for $\mathrm{V}$ genes was calculated by dividing the sum of all nucleotide mutations across all patients by the number of sequences used for the analysis. Hydrophobicity distribution comparisons were calculated as described in (11) (Fig. S5). The frequency distributions of human V genes in antiSARS-CoV-2 antibodies from this study was compared to $131,284,220$ IgH and IgL sequences generated by (44) and downloaded from cAb-Rep (45), a database of human shared BCR clonotypes available at https://cabrep.c2b2.columbia.edu/. Based on the 81 distinct $\mathrm{V}$ genes that make up the 1455 analyzed sequences from Ig repertoire of the three patients present in this study, we selected the $\operatorname{IgH}$ and $\operatorname{IgL}$ sequences from the database that are partially coded by the same $\mathrm{V}$ genes and counted them according to the constant region. The frequencies shown in (Fig. S6) are relative to the source and isotype analyzed. We used the two-sided binomial test to check whether the number of sequences belonging to a specific $\operatorname{IgHV}$ or IgLV gene in the repertoire is different according to the frequency of the same $\operatorname{IgV}$ gene in the database. Adjusted p-values were calculated using the false discovery rate (FDR) correction. Significant differences are denoted with stars. 
A Duration of Sx - anti-RBD IgA

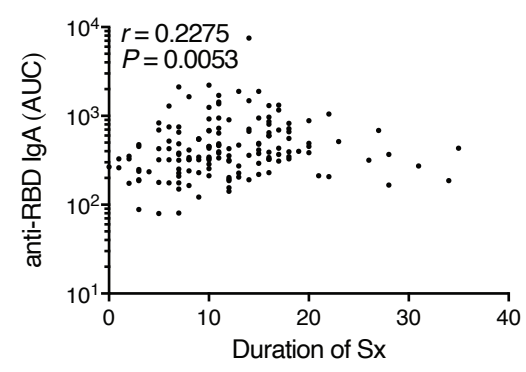

D GI-Sx - anti-RBD IgG

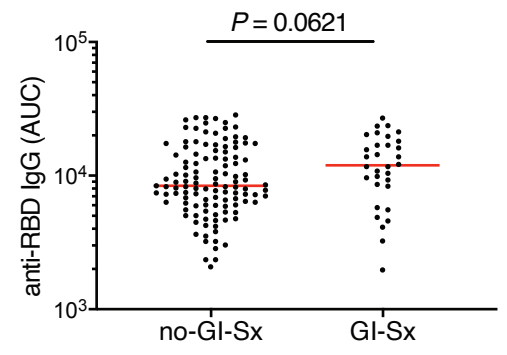

B

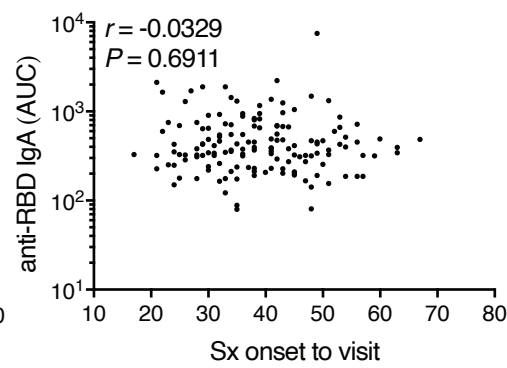

$\mathbf{E}$
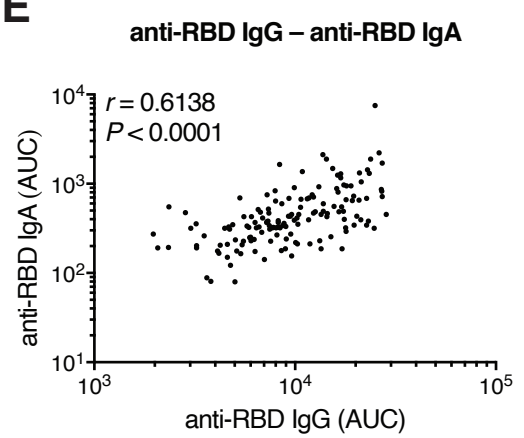

C Age - anti-RBD IgA

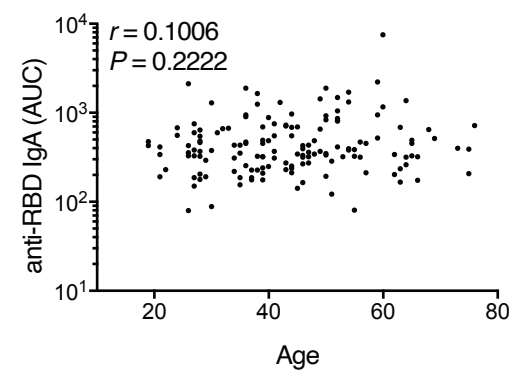

$\mathbf{F}$

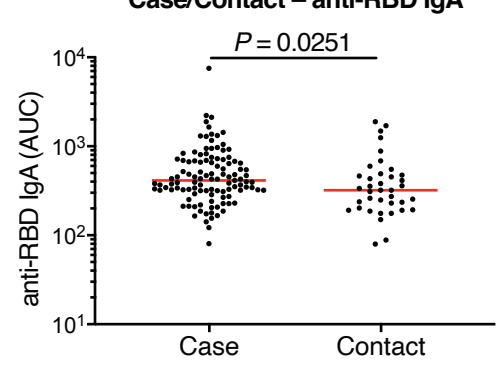

Fig. S1 Clinical correlates of plasma IgA antibody titers (A) Duration of Symptom (Sx) in days (X axis) plotted against normalized AUC for plasma IgA binding to RBD (Y axis). $r=0.2275, P=0.0053$. (B) Sx onset to time of sample collection in days plotted against normalized AUC for plasma IgA anti-RBD. $r=-0.0329$ and $P=0.6911$. (C) Age plotted against normalized AUC for plasma IgA anti-RBD. $r=0.1006, P=0.2222$. (D) Normalized AUC of plasma anti-RBD IgG ELISA for patients with gastrointestinal (GI) symptoms ( $\mathrm{n}=32$ ) and without GI symptoms (n=117); $P=0.0621$. (E) Normalized AUC of plasma anti-RBD IgG ELISA plotted against normalized AUC for plasma IgA anti-RBD. $r=0.6138, P<0.0001$. (F) Normalized AUC of plasma anti-RBD IgA ELISA for all cases (n $=111)$ and contacts $(\mathrm{n}=38)$ in the cohort; $P=0.0251$. For $(\mathrm{A}-\mathrm{C}, \mathrm{E})$ the correlations were analyzed by two-tailed Spearman's tests; For (D and F), Horizontal bars indicate median values. Statistical significance was determined using two-tailed Mann-Whitney U-tests. 


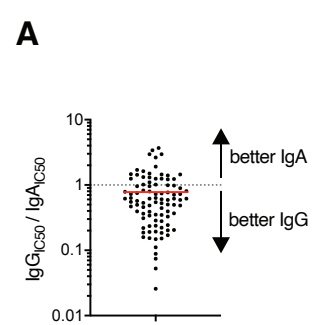

B
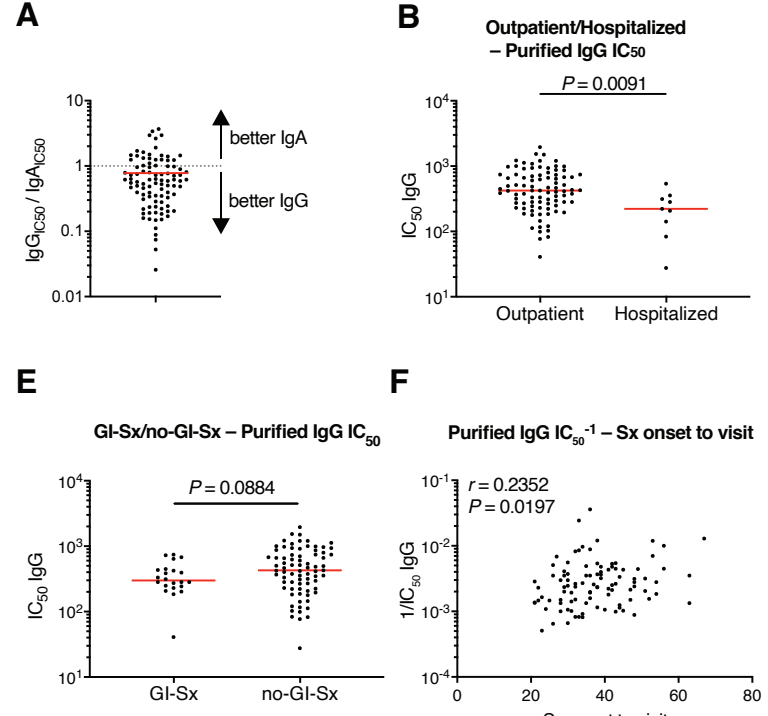

$\mathbf{F}$
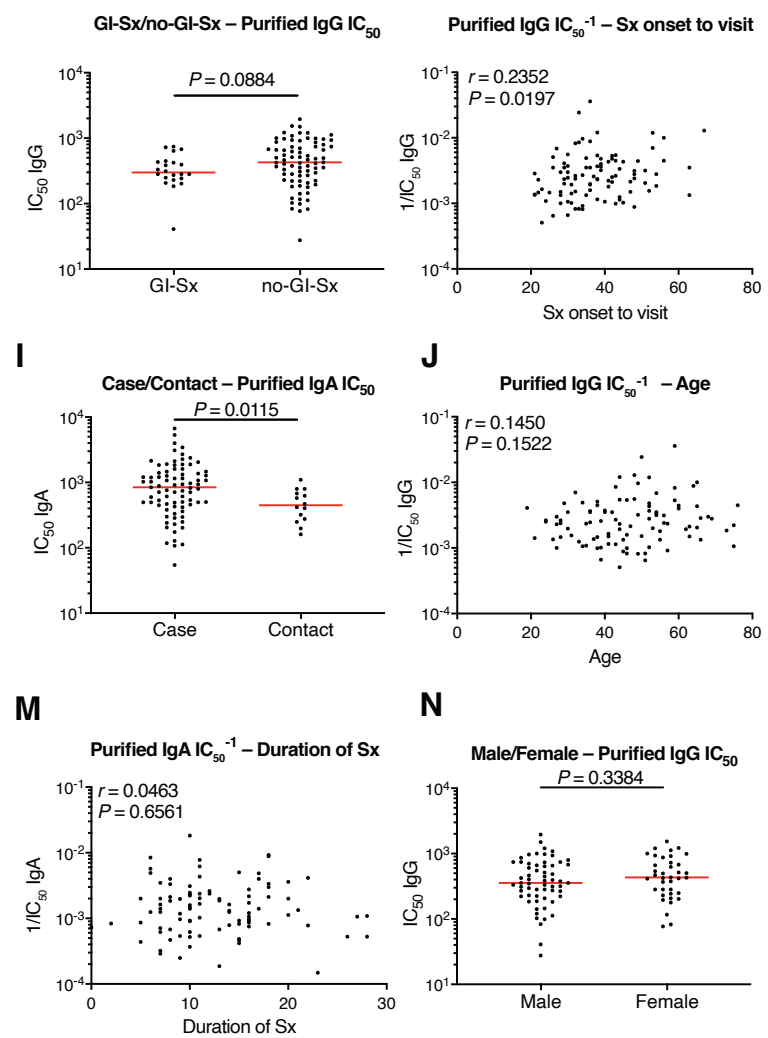

$\mathbf{N}$

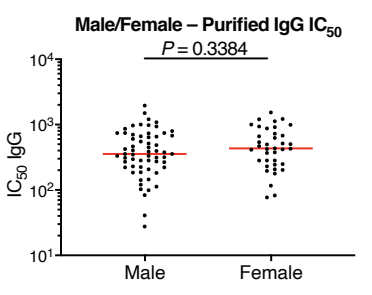

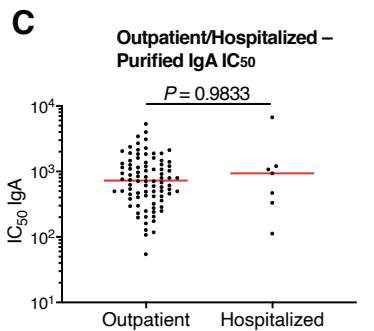

D Purified $\operatorname{lgA} \mathrm{IC}_{50}{ }^{-1}-\mathrm{Sx}$ severity

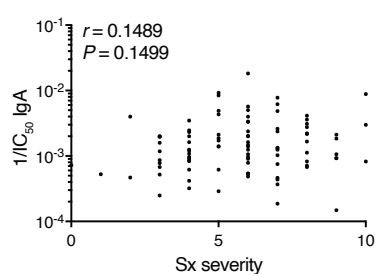

G

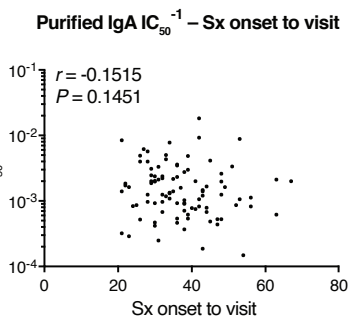

H

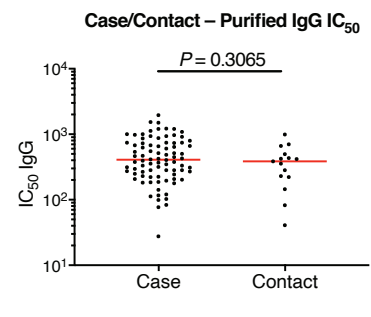

L
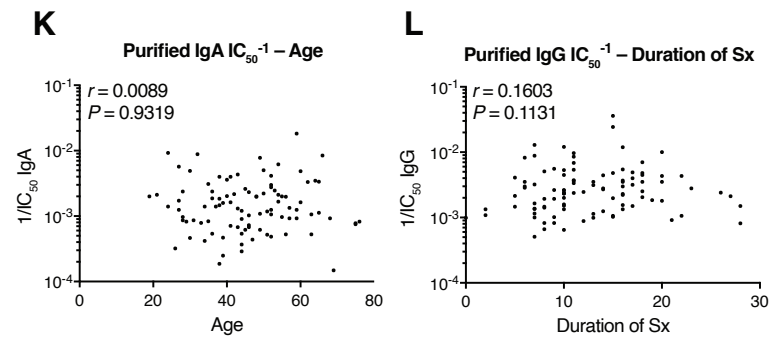

0

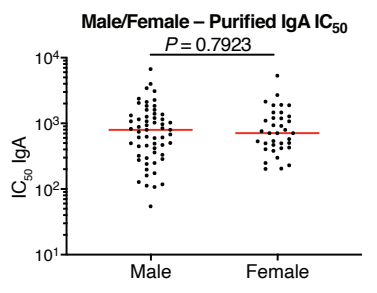

548

Fig. S2 Clinical correlates of plasma IgA/IgG neutralization (A) Ratio of pseudovirus neutralization $\mathrm{IC}_{50}$ values of purified $\operatorname{IgG}$ to $\operatorname{IgA}(\mathrm{n}=95)$. (B, C) Purified plasma $\operatorname{IgG}(\mathrm{B})$ and $\operatorname{Ig} A(\mathrm{C})$ pseudovirus neutralizing $\mathrm{IC}_{50}$ values for all outpatient $(\mathrm{n}=90)$ and hospitalized $(\mathrm{n}=9)$ participants in the cohort. (Fig. S2B, $P=0.0091)$ and (Fig. S2C, $P=$ 0.9833). (D) Purified plasma IgA $1 / \mathrm{IC}_{50}$ values plotted against symptom severity. $r=0.1489, P=0.1499$. (E) Purified plasma IgG IC 50 values for patients with GI symptoms $(\mathrm{n}=22)$ and without $\mathrm{GI}$ symptoms $(\mathrm{n}=77) ; p=0.0884$. $(\mathrm{F}, \mathrm{G})$ Sx onset to time of sample collection in days plotted against purified plasma $\operatorname{IgG}(\mathrm{F})$ and $\operatorname{IgA}(\mathrm{G})$ pseudovirus neutralization $1 / \mathrm{IC}_{50}$ values. (Fig. S2F, $r=0.2352, P=0.0197$ ) and (Fig. S2G, $\left.r=-0.1515, P=0.1451\right)$. (H, I) Purified plasma $\operatorname{IgG}(\mathrm{H})$ and $\operatorname{IgA}(\mathrm{I})$ pseudovirus neutralization $\mathrm{IC}_{50}$ values for all cases $(\mathrm{n}=84)$ and contacts $(\mathrm{n}=$ 15 ) in the cohort. (Fig. S2H, $P=0.3065$ ) and (Fig. S2I, $P=0.0115$ ). (J, K) Age plotted against purified plasma IgG 

$\operatorname{IgA(M)~pseudovirus~neutralization~1/IC50~values.~(Fig.~S2L,~} r=0.1603, P=0.1131$ ) and (Fig. S2M, $r=0.0463, P=$ females (n=38). (Fig. S2N, $P=0.3384)$ and (Fig.S2O, $P=0.7923)$. For (A), horizontal bars indicate mean value. For 


\section{A}
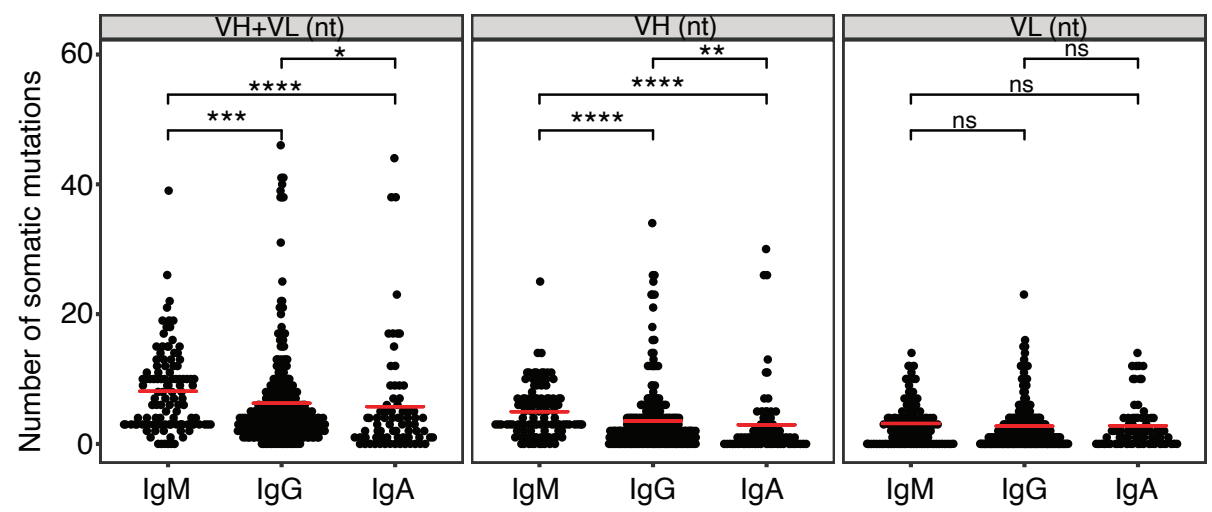

B

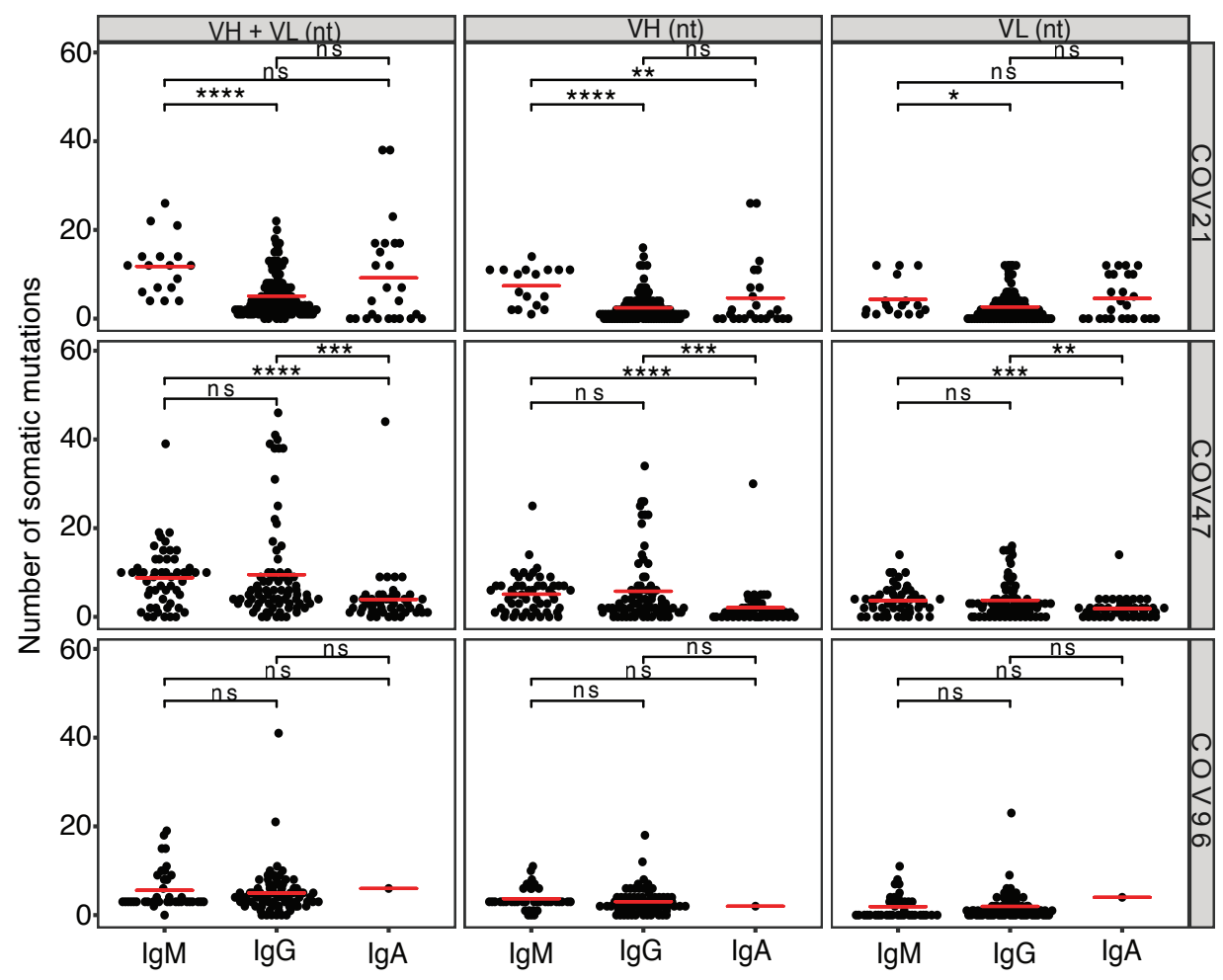

Fig. S3 Analysis of antibody somatic hypermutation

(A) The number of somatic nucleotide mutations ( $\mathrm{Y}$ axis) at the IGVH and IGVL for IgM, IgG and IgA antibodies

IGVL. (n=455). (B) Same as (A) but for each individual. 


\section{A}
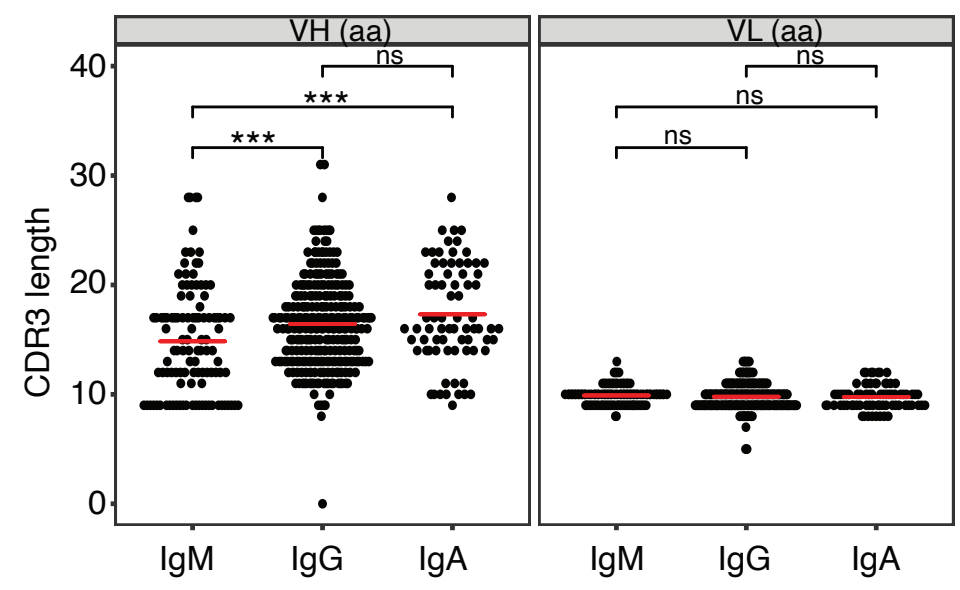

B

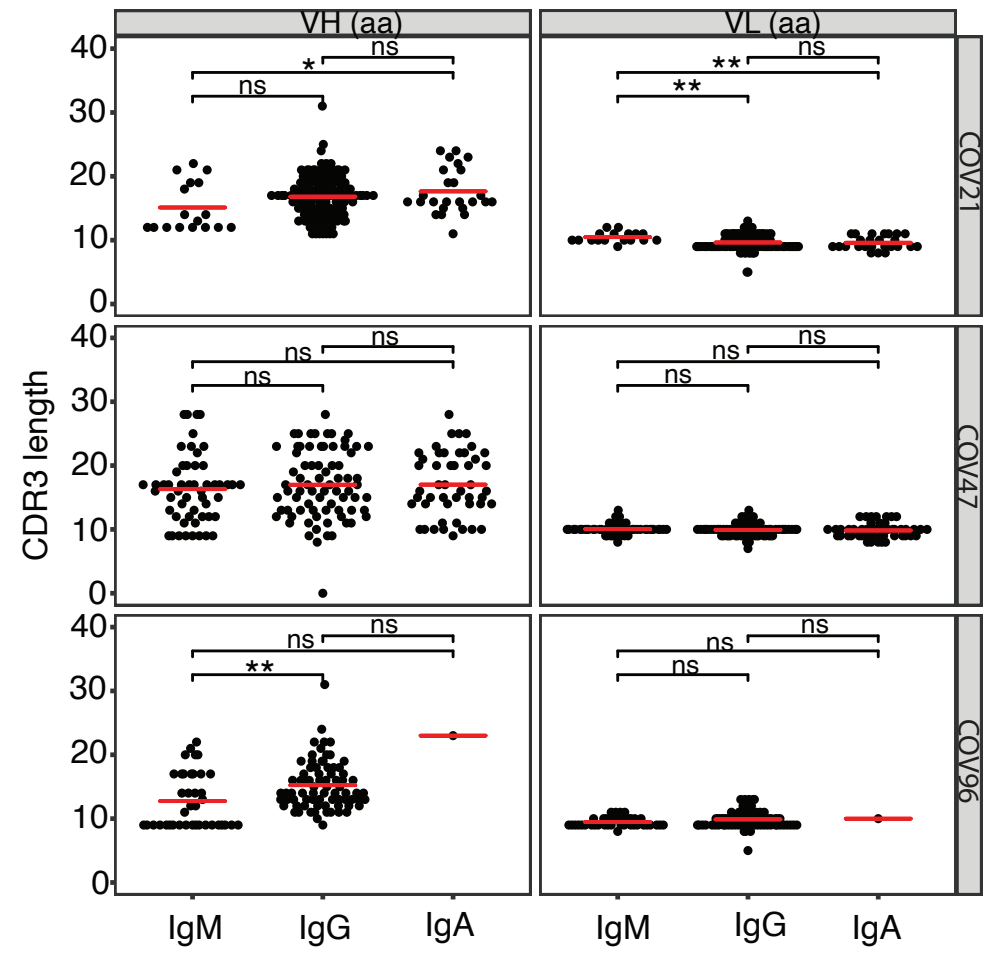

573 (A) IGVH and IGVL CDR3s length (Y axis) for IgM, IgG and IgA (X axis). (B) Same as (A) but for each $574 \quad$ individual. The horizontal bars indicate the mean. 

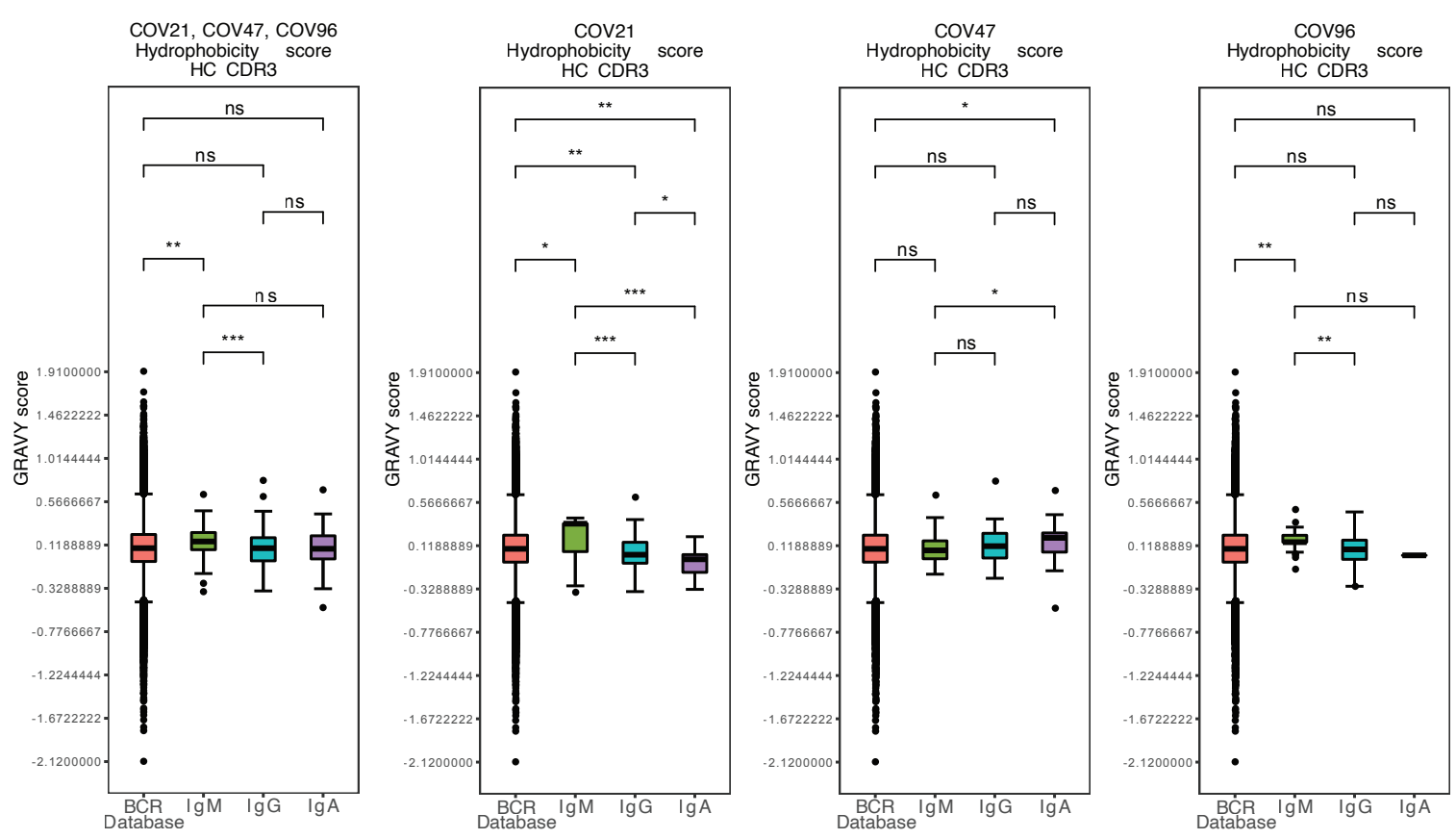

Fig. S5 Analysis of antibody CDR3 hydrophobicity

Distribution of the hydrophobicity GRAVY scores at the IGH CDR3 in antibody sequences from this study

580 compared to a public database (see Methods for statistical analysis). The box limits are at the lower and upper outliers. 
bioRxiv preprint doi: https://doi.org/10.1101/2020.09.09.288555; this version posted September 9, 2020. The copyright holder for this preprint (which was not certified by peer review) is the author/funder, who has granted bioRxiv a license to display the preprint in perpetuity. It is made available under aCC-BY-NC-ND 4.0 International license.
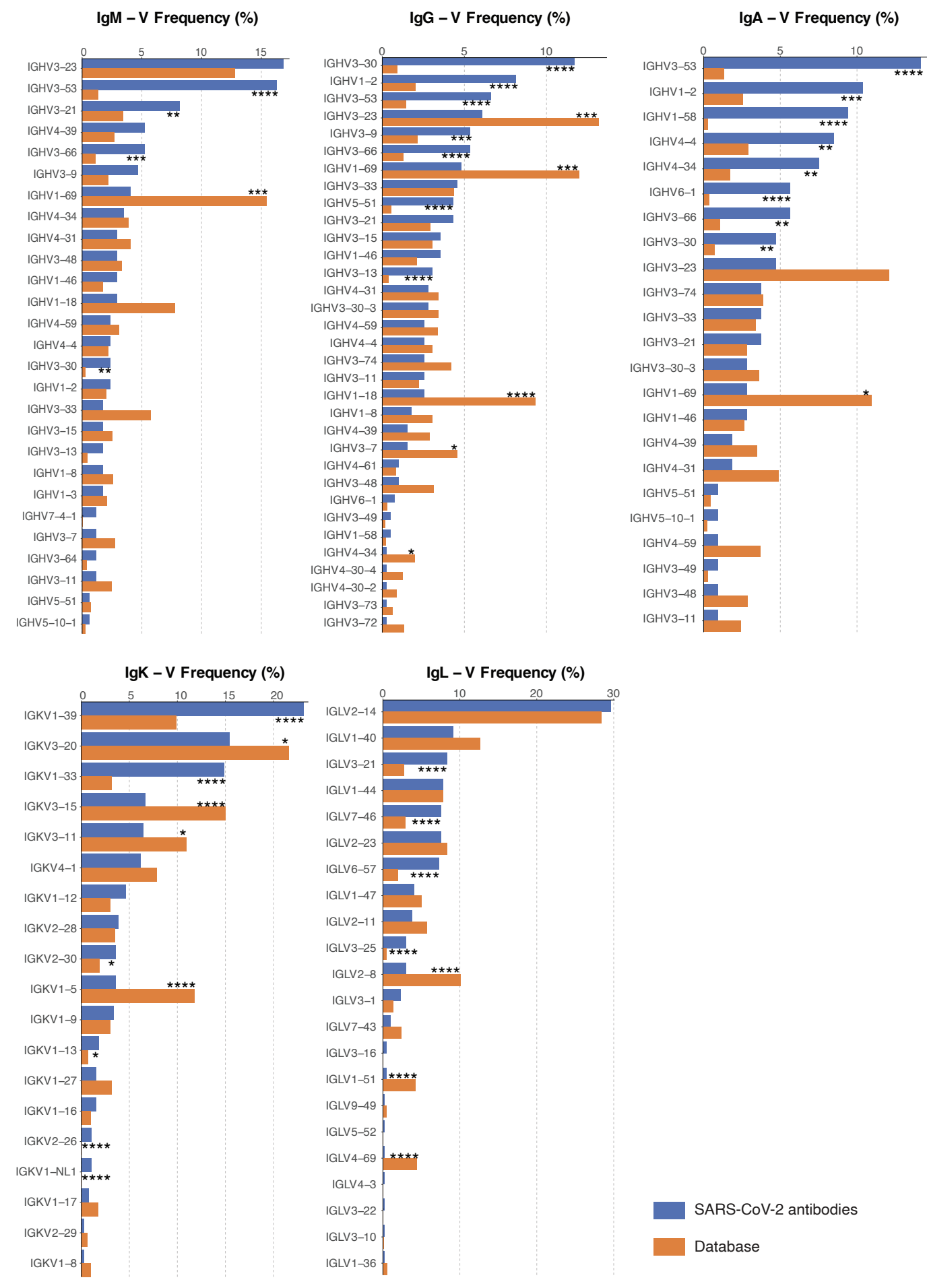

SARS-CoV-2 antibodies

Database

Fig. S6 Frequency distributions of human V genes.

586 Comparison of the frequency distributions of human $\mathrm{V}$ genes for heavy chain (IgM, IgG and IgA) and light chains of anti-SARS-CoV-2 antibodies from this study and from a database of shared clonotypes of human B cell receptor 
bioRxiv preprint doi: https://doi.org/10.1101/2020.09.09.288555; this version posted September 9, 2020. The copyright holder for this preprint

(which was not certified by peer review) is the author/funder, who has granted bioRxiv a license to display the preprint in perpetuity. It is made available under aCC-BY-NC-ND 4.0 International license.

generated by Cinque Soto et al. (44). Statistical significance was determined using the two-sided binomial test.

Significant differences are denoted with stars.

590 
A
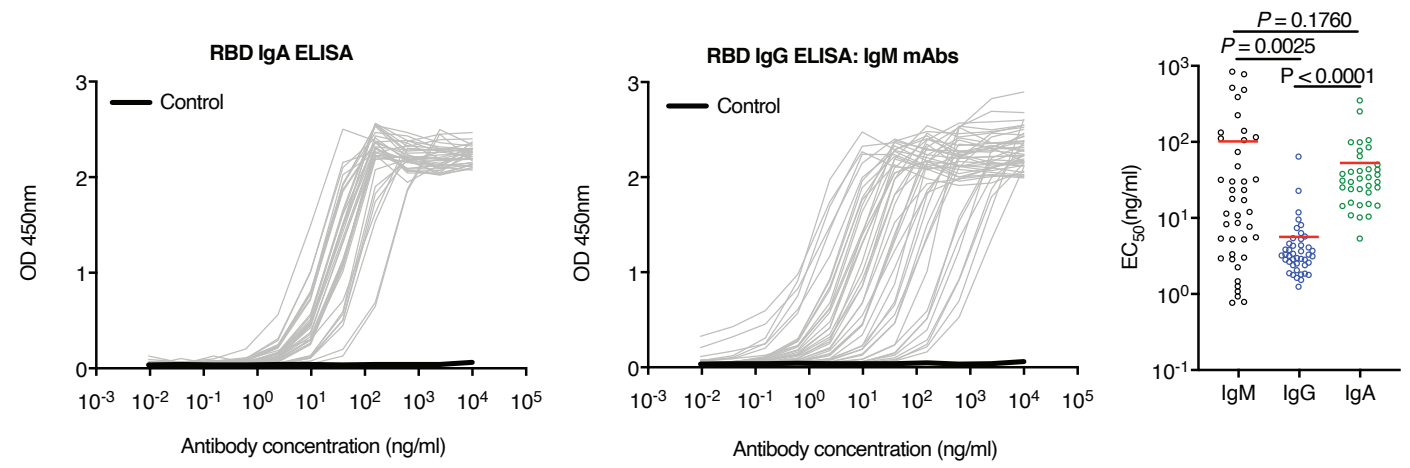

B
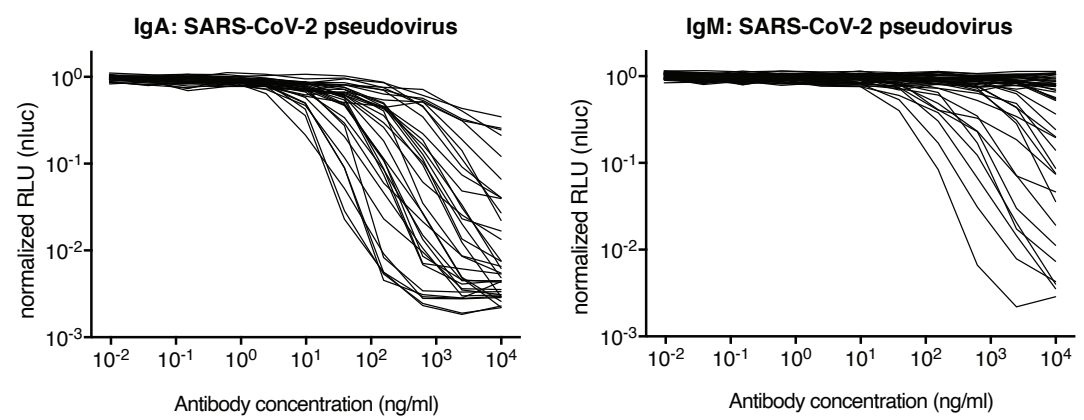

Fig. S7 Binding and neutralizing activity of anti-SARS-CoV-2 RBD IgA and IgM monomers.

(A) Binding profiles of $35 \operatorname{IgA}$ and 46 IgM monoclonals against RBD. Comparisons of IgM, published IgG (11) and 
600

601

602

603

604

605

606
A

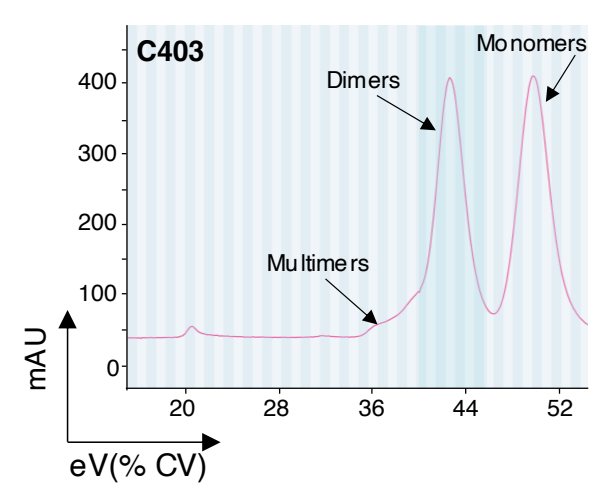

B

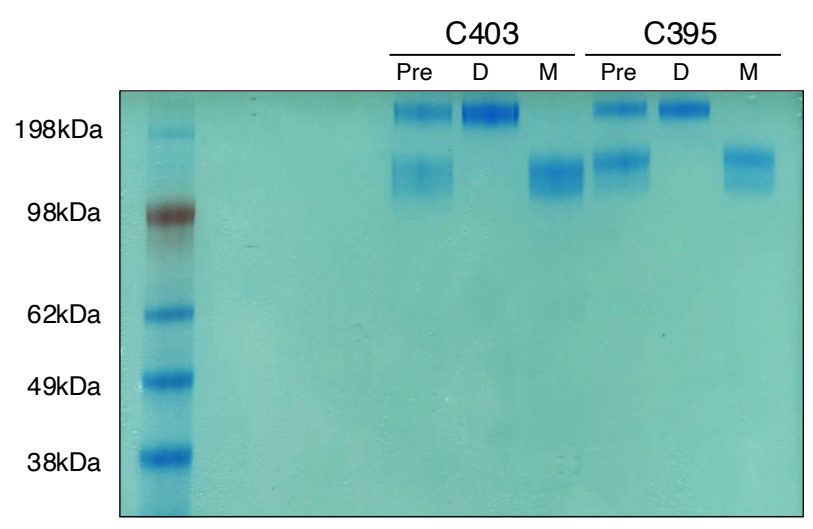

Fig. S8 Purification of Dimeric IgA by Size Exclusion Chromatography. (A) Monomers and dimers of IgA1 or $\operatorname{IgA} 2$ were separated using a Superdex 200 (Cytiva) with PBS at a flow rate of $0.5 \mathrm{ml} / \mathrm{min}$. Representative example: $\mathrm{C} 403$. The $\mathrm{X}$ axis is elution volume (eV) as a percent of Column volume. The $\mathrm{Y}$ axis is absorption at $280 \mathrm{~nm}(\mathrm{mAU})$.

(B) Coomassie Blue stained non-reducing SDS-PAGE gel of pre-separation antibody mixture (Pre), isolated dimers (D) and monomers (M). 
bioRxiv preprint doi: https://doi.org/10.1101/2020 09.09.28855. this version posted September 9,2020. The copyright holder for this preprint (which was not certified by peer review) is the author/funder, who has granted bioRxiv a license to display the preprint in perpetuity. It is made available under aCC-BY-NC-ND 4.0 International license.

A

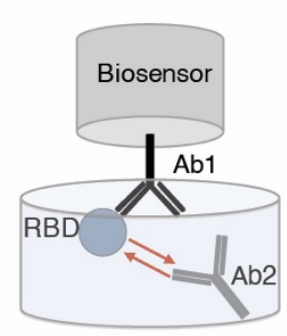

B

\begin{tabular}{|c|c|c|c|c|c|c|c|c|c|c|c|c|c|}
\hline & \multicolumn{13}{|c|}{$\mathrm{Ab} 2$} \\
\hline & 144 & 399 & 403 & 121 & 408 & 387 & 402 & 395 & 437 & 135 & 404 & 405 & CR3022 \\
\hline 144 & 0 & 0.3 & 0 & -0.1 & -0.2 & -0.1 & -0.1 & -0.1 & -0.3 & 1 & -0.2 & -0.1 & 1.3 \\
\hline 399 & -0.2 & 0 & & -0.1 & & & & & & 0.6 & & & 0.8 \\
\hline 403 & 0.1 & & 0 & 0 & & & & & & 1.2 & & & 1.3 \\
\hline 121 & 1.4 & 1.3 & 1 & 0 & -0.1 & -0.1 & 0 & 0 & 0 & 2.5 & -0.1 & 0.7 & 3 \\
\hline 408 & 1.1 & & & 0 & 0 & & & & & 2.6 & & & 2.9 \\
\hline 387 & \begin{tabular}{|l|}
1.1 \\
\end{tabular} & & & 0 & & 0 & & & & 2.6 & & & 2.7 \\
\hline 402 & 0.8 & & & -0.3 & & & 0 & & & 2.7 & & & 2.5 \\
\hline 395 & 1 & & & -0.2 & & & & 0 & & 2.7 & & & 3.2 \\
\hline 437 & 1.9 & & & 0.5 & & & & & 0 & 2.8 & & & 2.8 \\
\hline 135 & 1.6 & 1.9 & 2.2 & 1.7 & 1.2 & 1.7 & 1.8 & 1.8 & 1.6 & 0 & -0.3 & 0.1 & 1.7 \\
\hline 404 & 1.5 & & & 0 & & & & & & 1.1 & 0 & & 3.3 \\
\hline 405 & 0.2 & & & 0.2 & & & & & & 0.3 & & 0 & 0.7 \\
\hline CR3022 & 2.8 & 3.3 & 2.8 & 2.9 & 2.7 & 2.2 & 2.4 & 2.5 & 1.9 & 2.8 & 2.1 & 2.8 & 0 \\
\hline
\end{tabular}

C GROUP 1
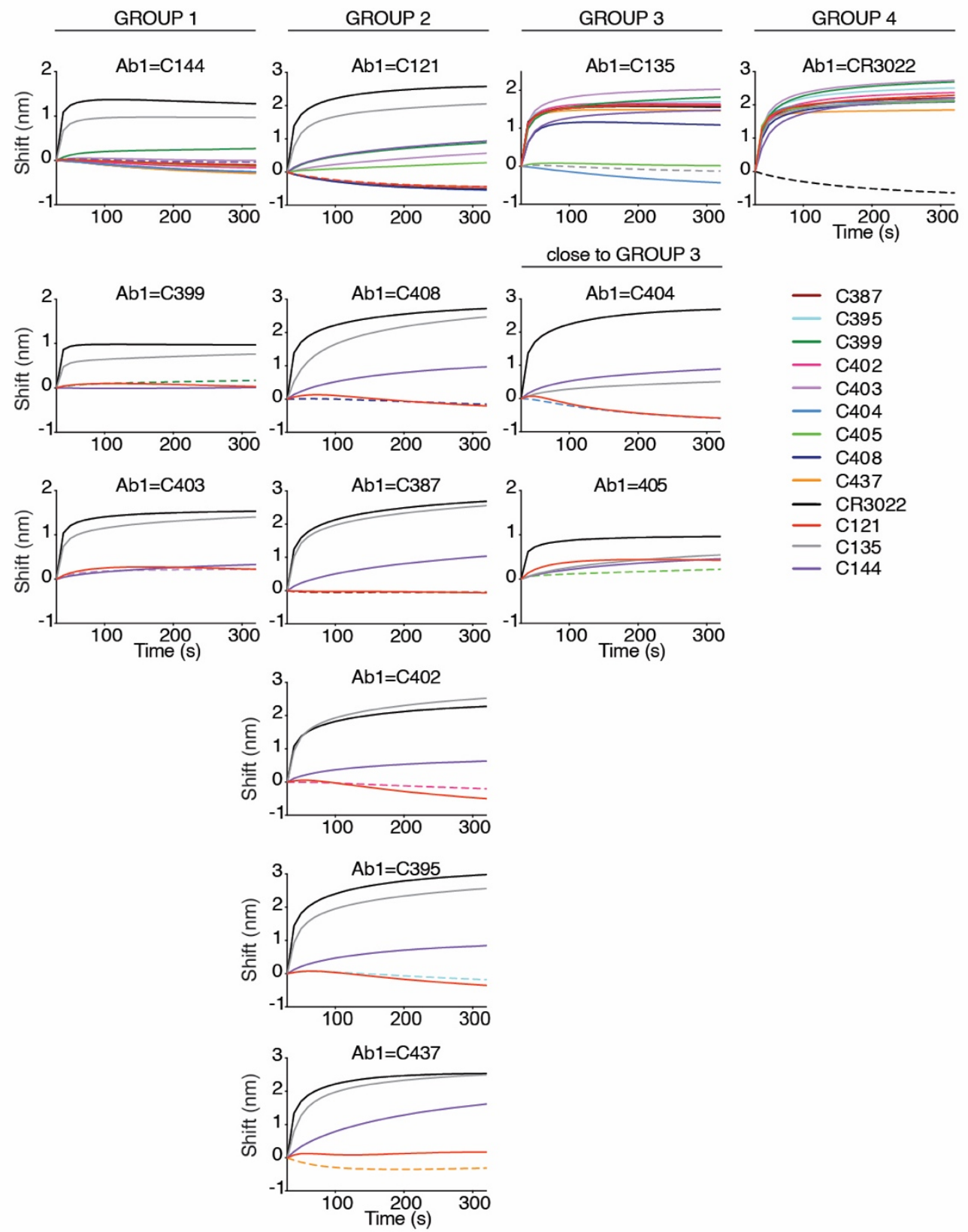
Fig. S9 Biolayer interferometry experiment. (A) Diagrammatic representation of biolayer interferometry experiment. (B) The table displays the shift in nanometers after second antibody (Ab2) binding to the antigen in the presence of the first antibody (Ab1). Values are normalized by the subtraction of the autologous antibody control. (C) Second antibody (Ab2) binding to preformed first antibody (Ab1)-RBD complexes. Dotted line denotes when $\mathrm{Ab} 1$ and $\mathrm{Ab} 2$ are the same, and $\mathrm{Ab} 2$ is according to the colour-coding in Fig. 4B (right panel). 
A
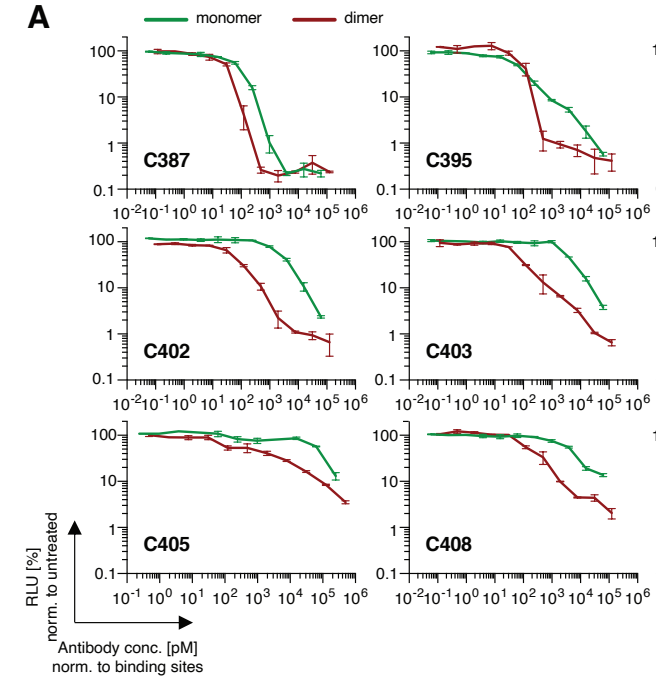

0.17
$10^{-2} 10^{-1} 10^{0} 10^{1} 10^{2} 10^{3} 10^{4} 10^{5} 10^{6} \quad 170^{6}-10^{-1} 10^{0} 10^{1} 10^{2} 10^{3} 10^{4} 10^{5} 10^{6}$

D
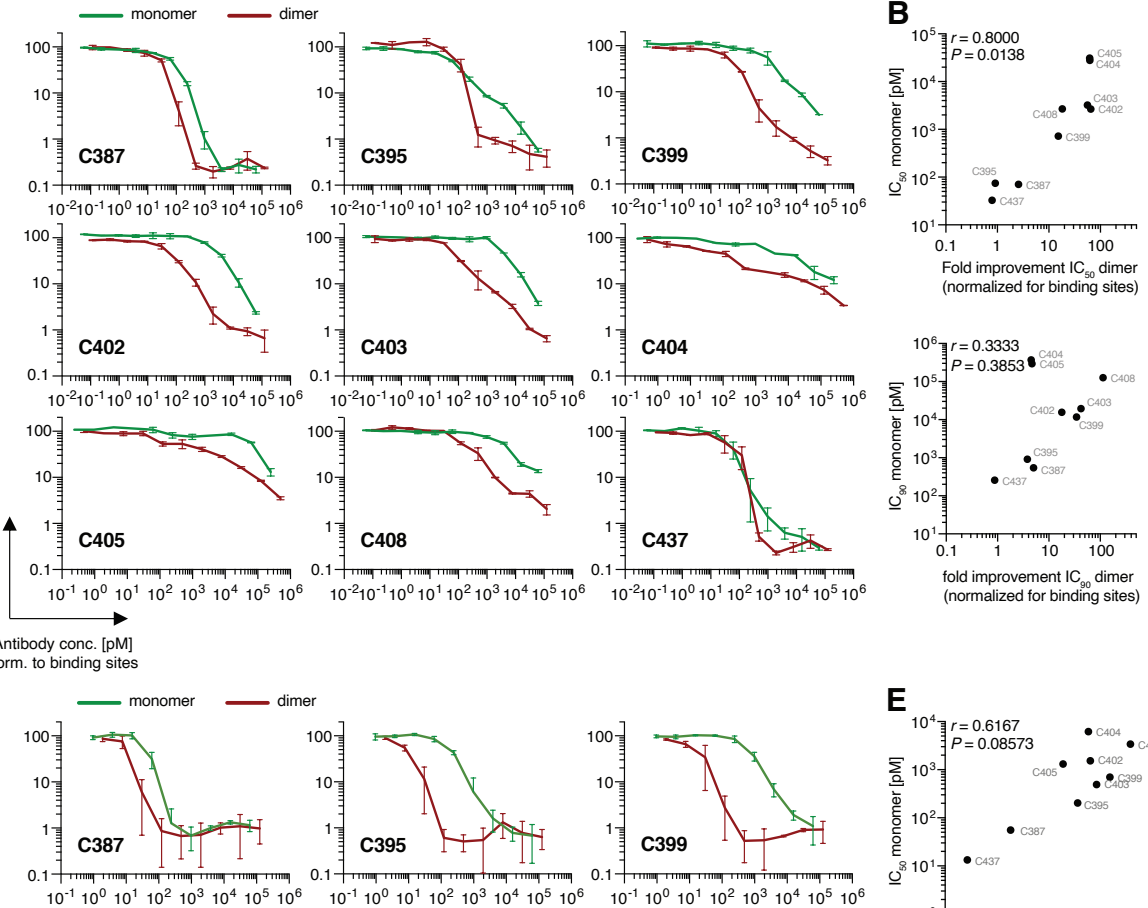

Fold improvement $\mathrm{IC}_{50}$ dimer
(normalized for binding sites)
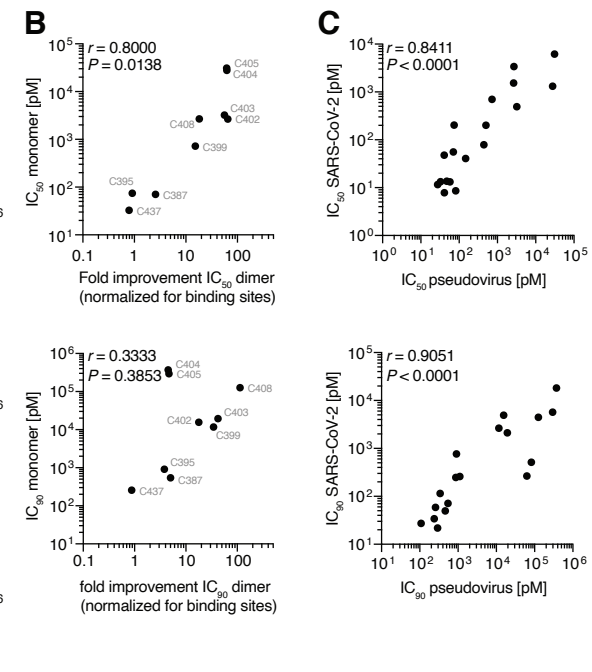

Fig. S10 Neutralizing activity of monoclonal monomeric and dimeric IgAs 

normalized percentage of SARS-CoV-2 positive VeroE6 cells $48 \mathrm{~h}$ after infection with SARS-CoV-2 authentic virus in the presence of increasing concentrations of abovementioned antibodies in their dimeric and monomeric form. (E) were analyzed by two-tailed Spearman's tests.

Auxiliary Supplementary Material.

Table S2. Sequences of antibodies from isotype shared clones

Auxiliary Supplementary Material.

Table S3. Inhibitory concentrations of monoclonal antibodies from isotype shared clones

\begin{tabular}{|c|c|c|c|c|c|c|c|c|c|}
\hline Patient ID & $\lg M$ & IC50(ng/ml) & IC90(ng/ml) & $\lg G$ & IC50(ng/ml)* & IC90(ng/ml)* & $\lg A$ & IC50(ng/ml) & IC90(ng/ml) \\
\hline \multirow{2}{*}{ Cov21 } & - & & & CG002 & 8.88 & 37.61 & CA386 & 5.76 & 123.33 \\
\hline & - & & & CG005 & 60.49 & 205.20 & CA387 & 9.68 & 129.87 \\
\hline \multirow{7}{*}{ COV47 } & - & & & CG144 & 6.91 & 29.66 & CA394 & 13.06 & 371.86 \\
\hline & CM169 & UD & UD & CG148 & $>1000$ & $>1000$ & - & & \\
\hline & CM170 & 5806 & 37082 & CG171 & 5250 & 17156 & CA457 & 1721.6 & 298325.6 \\
\hline & - & & & CG379 & 126.98 & 2368.18 & CA403 & 23.88 & 126.05 \\
\hline & CM381 & UD & UD & CG160 & $>1000$ & $>1000$ & - & & \\
\hline & СM349 & 844.59 & 26446.73 & CG380 & 2.94 & 35.96 & - & & \\
\hline & CM311 & 126.85 & 846.13 & CG151 & 31.79 & $>1000$ & CA390 & 417.42 & 46597.44 \\
\hline \multirow{2}{*}{ Cov96 } & CM194 & UD & UD & CG382 & 42.92 & 122.33 & - & & \\
\hline & CM365 & 1226.09 & 8268.46 & CG202 & $>1000$ & $>1000$ & - & & \\
\hline
\end{tabular}

641

642

643

644

UD=Undetectable

*(Robbiani et al. 2020)

\section{Table S4. Sequences of cloned recombinant antibodies}

Auxiliary Supplementary Material.

Table S5. Effective and inhibitory concentrations of monoclonal antibodies 
$646 \quad$ Auxiliary Supplementary Material.

647

648 Table S6. Inhibitory concentrations of monoclonal IgA monomers and dimers

Table S6. Inhibitory concentrations of monoclonal IgA monomers and dimers

\begin{tabular}{|c|c|c|c|c|c|c|c|c|}
\hline \multirow[b]{3}{*}{ Antibody ID } & \multicolumn{4}{|c|}{ SARS-CoV-2 pseudovirus } & \multicolumn{4}{|c|}{ SARS-CoV-2 } \\
\hline & \multicolumn{2}{|c|}{ IC50 (pM) } & \multicolumn{2}{|c|}{ IC90 (pM) } & \multicolumn{2}{|c|}{ IC50 (pM) } & \multicolumn{2}{|c|}{ IC90 (pM) } \\
\hline & monomer & dimer & monomer & dimer & monomer & dimer & monomer & dimer \\
\hline C387 & 70.68 & 27.46 & 543.91 & 108.06 & 55.74 & 11.64 & 71.46 & 27.37 \\
\hline С395 & 74.15 & 81.64 & 909.67 & 239.03 & 203.72 & 8.59 & 769.49 & 34.10 \\
\hline Сз99 & 722.84 & 47.48 & 11692.05 & 339.46 & 700.38 & 13.67 & 2636.98 & 114.74 \\
\hline $\mathrm{C} 402$ & 2652.52 & 40.86 & 15603.86 & 874.99 & 1536.24 & 47.90 & 4939.53 & 247.79 \\
\hline $\mathrm{C} 403$ & 3222.29 & 57.62 & 19499.80 & 461.45 & 491.11 & 13.18 & 2115.67 & 49.85 \\
\hline C404 & 31112.25 & 502.11 & 371134.20 & 82318.65 & 6182.08 & 201.78 & 18271.60 & 514.05 \\
\hline C405 & 27801.09 & 444.36 & 294918.48 & 62867.98 & 1312.88 & 78.57 & 5725.29 & 266.04 \\
\hline C408 & 2691.09 & 147.89 & 126130.74 & 1114.44 & 3392.62 & 40.51 & 4458.13 & 259.84 \\
\hline $\mathrm{C} 437$ & 32.67 & 41.18 & 258.08 & 292.35 & 13.32 & 7.84 & 58.85 & 21.82 \\
\hline
\end{tabular}

IC50/90 values for dimers were adjusted for number of binding sites

649

Table S7. Primers

651 Auxiliary Supplementary Material.

652

653

654

655

656 